\title{
Wastewater Treatment by Catalytic Wet Peroxidation Using Nano Gold-Based Catalysts: A Review
}

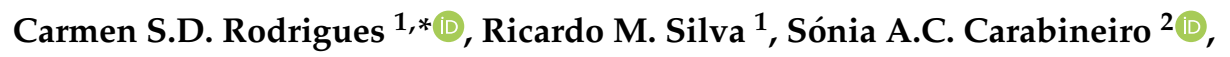 \\ F.J. Maldonado-Hódar ${ }^{3}$ (D) and Luís M. Madeira ${ }^{1}$ (D) \\ 1 LEPABE - Laboratory for Process Engineering, Environment, Biotechnology and Energy, \\ Faculty of Engineering, University of Porto, Rua Dr. Roberto Frias, 4200-465 Porto, Portugal; \\ up201306722@fe.up.pt (R.M.S.); mmadeira@fe.up.pt (L.M.M.) \\ 2 LCM - Laboratory of Catalysis and Materials, Associate Laboratory LSRE/LCM, Department of Chemical \\ Engineering, Faculty of Engineering, University of Porto, R. Dr. Roberto Frias, 4200-465 Porto, Portugal; \\ scarabin@fe.up.pt \\ 3 Department of Inorganic Chemistry, Faculty of Sciences, University of Granada, Avenida de Fuente Nueva, \\ s/n 18071 Granada, Spain; fjmaldon@ugr.es \\ * Correspondence: csdr@fe.up.pt; Tel.: +351-22-041-4851
}

Received: 30 April 2019; Accepted: 20 May 2019; Published: 23 May 2019

check for updates

\begin{abstract}
Nowadays, there is an increasing interest in the development of promising, efficient, and environmentally friendly wastewater treatment technologies. Among them are the advanced oxidation processes (AOPs), in particular, catalytic wet peroxidation (CWPO), assisted or not by radiation. One of the challenges for the industrial application of this process is the development of stable and efficient catalysts, without leaching of the metal to the aqueous phase during the treatment. Gold catalysts, in particular, have attracted much attention from researchers because they show these characteristics. Recently, numerous studies have been reported in the literature regarding the preparation of gold catalysts supported on various supports and testing their catalytic performance in the treatment of real wastewaters or model pollutants by CWPO. This review summarizes this research; the properties of such catalysts and their expected effects on the overall efficiency of the CWPO process, together with a description of the effect of operational variables (such as $\mathrm{pH}$, temperature, oxidant concentration, catalyst, and gold content). In addition, an overview is given of the main technical issues of this process aiming at its industrial application, namely the possibility of using the catalyst in continuous flow reactors. Such considerations will provide useful information for a faster and more effective analysis and optimization of the CWPO process.
\end{abstract}

Keywords: catalytic wet peroxidation; radiation; gold-based catalysts; wastewater treatment; advanced oxidation processes

\section{Introduction}

The world's population growth and increasing industrial development led to the intense usage of natural resources with the water bodies being used as a final destination for wastewater containing pollutants [1-3]. The discharge of untreated wastewater introduces persistent contaminants into the environment, some examples being metals, organic, and inorganic compounds [4-6], which have harmful effects on ecology and public health [7].

In an attempt to minimize the impacts of effluent discharges, the European Union Water Framework Directive (EU-WFD), in 2000, imposed maximum permissible values for ecotoxic or possibly ecotoxic substances [8]. Thus, it is mandatory to adopt practical, efficient, and low-cost effluent purification technologies $[9,10]$, which will allow the complete elimination or, at least, reduction of the contaminants 
concentration up to the limit values imposed by legislation [10,11], before wastewaters are discharged into water bodies.

The wastewaters can be treated by physical-chemical processes, such as sedimentation, coagulation/flocculation, filtration, adsorption, ultrafiltration, reverse osmosis, ion exchange, or chemical precipitation [12,13], by biological degradation [13-15], and/or by conventional oxidative processes, which degrade the pollutant by the action of oxygen or other oxidants, such as hydrogen peroxide, ozone, and permanganate [16-18]. Physical-chemical processes are not very appealing because the pollutants are concentrated at another phase, which requires a subsequent treatment [10]. Biological degradation, although economically advantageous, is inefficient since the compounds present in effluents are very often toxic and/or non-biodegradable $[19,20]$. Moreover, conventional oxidative processes might not have enough capacity to completely oxidize refractory compounds with high chemical stability and, therefore, there is a high risk of intermediate products being formed during oxidation, which can be even more toxic than the initial ones [21-23].

Advanced oxidation processes (AOPs) are emergent and attractive treatment technologies to degrade compounds with high chemical stability, toxicity, and non-biodegradability [10,24]. AOPs generate the hydroxyl radical $\left(\mathrm{HO}^{\bullet}\right)$, responsible for oxidizing refractory organic compounds into non-toxic products, such as $\mathrm{CO}_{2}$ and $\mathrm{H}_{2} \mathrm{O}$ [10,25-27]. Given the high efficiency of the hydroxyl radical, the AOPs have been widely used, not only in wastewater treatment $[9,19,28-30]$, but also in soil and sediment remediation [31,32], decontamination of gaseous effluents containing volatile organic compounds and elimination of odors [33-36], water and groundwater treatment [37-39], and conditioning of municipal sludge [40,41].

Several AOPs are available, as will be detailed in the next section, that use different oxidants, with or without catalysts, in the presence of absence of radiation. Herein, we will focus on the catalytic wet peroxidation (CWPO) process using nano gold-based catalysts for wastewater treatment. This process presents several advantages compared to other AOPs, namely: it uses environmentally friendly reagents, does not require sophisticated equipment, and is operated under mild conditions of pressure and temperature. Moreover, catalysis by gold presents additional advantages, such as non-leaching of the metal to the treated effluent and efficient and stable performance, which are important for industrial applications.

A survey of the catalyst properties, operating conditions, and their effect on the efficiency of the process will be discussed. To the best of the authors knowledge, such review has not yet been reported in the literature.

\section{Advanced Oxidation Processes}

As mentioned above, AOPs are based on the formation of the hydroxyl radical. This radical has a high oxidation potential $(2.8 \mathrm{eV}[42,43])$, being immediately below the fluorine (see Table 1$)$, and exhibits high oxidation reaction rates, compared to traditional oxidants, such as chlorine, hydrogen peroxide, or potassium permanganate [11].

Table 1. Standard oxidation potential of some chemicals species (adapted from $[42,43]$ ).

\begin{tabular}{lc}
\hline Chemical Species & Oxidation Potential (eV) \\
\hline Fluorine & 3.03 \\
Hydroxyl radical & 2.80 \\
Atomic oxygen & 2.42 \\
Ozone & 2.07 \\
Hydrogen peroxide & 1.77 \\
Potassium permanganate & 1.67 \\
Hypobromous acid & 1.59 \\
Chlorine dioxide & 1.50 \\
Hypochlorous acid & 1.49 \\
Chlorine & 1.36 \\
Bromine & 1.09 \\
Iodine & 0.54 \\
\hline
\end{tabular}


The hydroxyl radicals are able to react with almost every type of organic compounds [27], leading, in some cases, to their complete oxidation into $\mathrm{CO}_{2}$ and $\mathrm{H}_{2} \mathrm{O}[10,25,26]$. However, partial oxidation can be the main route, usually leading to more biodegradable products $[25,26]$. The oxidation of organic matter (RH) by hydroxyl radicals occurs by three mechanisms [19,42]: radical addition (Equation (1)), electron transfer to radicals (Equation (2)), and hydrogen abstraction (Equation (3)) that generates organic radicals, which yield peroxyl radicals by addition of molecular oxygen (Equation (4)).

$$
\begin{gathered}
\mathrm{HO}^{\bullet}+\mathrm{RH} \rightarrow \mathrm{RH}_{2} \mathrm{O} \\
\mathrm{HO}^{\bullet}+\mathrm{RH} \rightarrow \mathrm{RH}^{\bullet+}+\mathrm{OH}^{-} \\
\mathrm{HO}+\mathrm{RH} \rightarrow \mathrm{R}^{\bullet}+\mathrm{H}_{2} \mathrm{O} \\
\mathrm{R}^{\bullet}+\mathrm{O}_{2} \rightarrow \mathrm{RO}_{2}^{\bullet}
\end{gathered}
$$

A large number of technologies are responsible for the generation of the hydroxyl radicals. Most of them use a combination of oxidants, such as ozone or/and hydrogen peroxide, semiconductors (like titanium dioxide or zinc oxide) or catalysts (e.g., transition metal ions), and irradiation (ultraviolet and/or visible, sunlight or ultrasounds), as shown in Figure $1[11,19,24,44]$. Processes in which the catalyst is dissolved in the effluent are called homogeneous, but when the catalyst is supported on a solid matrix they are designated as heterogeneous.

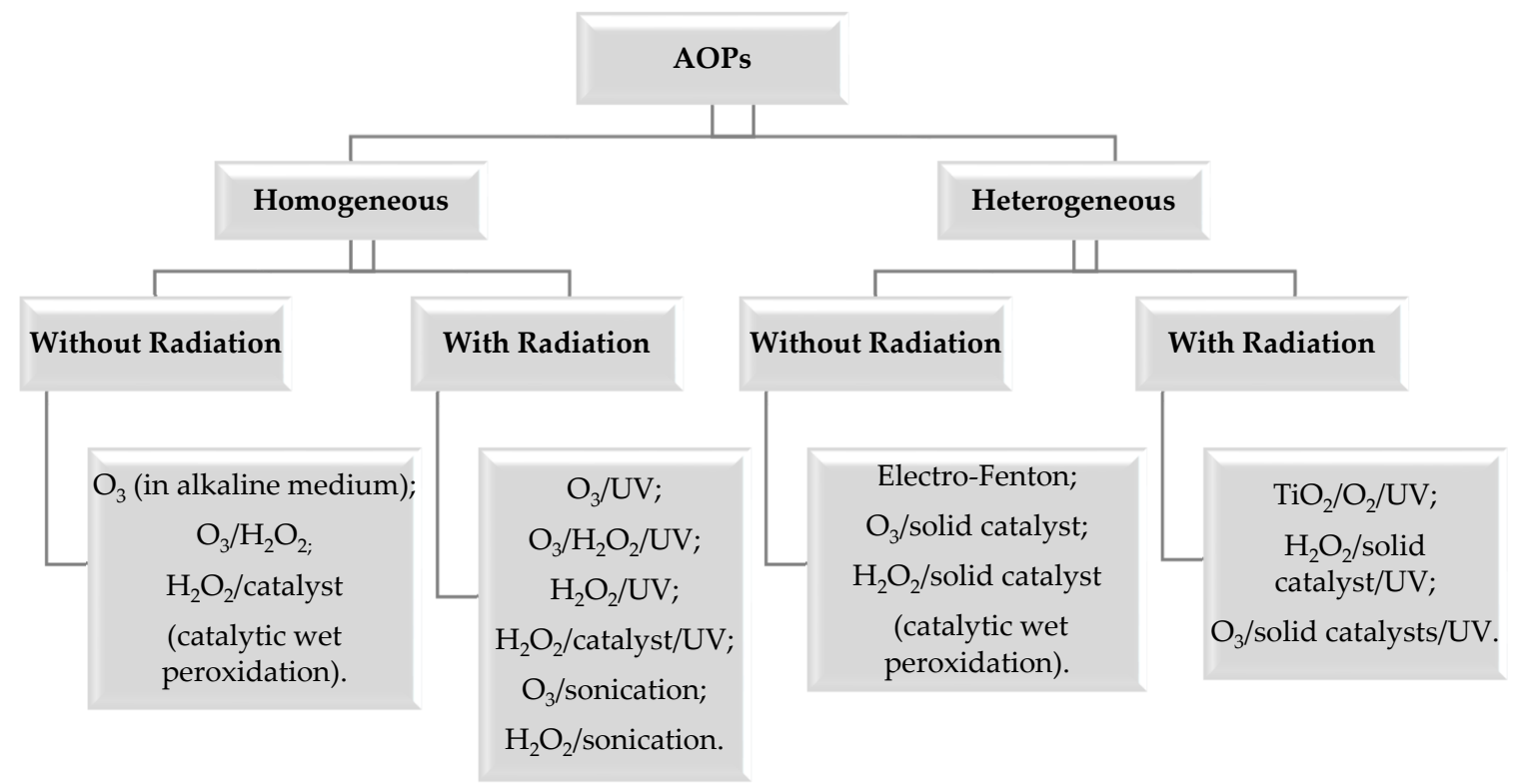

Figure 1. Some relevant advanced oxidation processes (AOPs) for wastewater treatment (adapted from Poyatos et al. [24]).

The benefits of AOPs are: the possibility of degrading pollutants in lowa wide range of concentrations, the easiness in combining with other processes, such as biological and adsorption, and also the fact that some of them are conducted at near ambient pressure and temperature $[9,44]$. Nevertheless, each AOP has characteristic drawbacks associated. As an example, when using ozone-based processes, sophisticated equipment is required, such as an ozone generator, a cooling system, pre-and post-treatment setups to dry the air fed to the ozonator and to reduce the residual ozone in the gas off, respectively [45], which increases the implementation and operation costs. The processes that use radiation have high expenses of energy consumption, in addition to the costs of the installation and equipment. However, when effective photocatalysts are used, this charge can be null in countries with high incidence of solar radiation, which can replace artificial sources. Another disadvantage 
of these processes is that the compounds present in the effluent can filtrate or absorb the radiation, limiting its reaction with the oxidant [46], which decreases the treatment efficiency.

The CWPO process is known for its simplicity, as it does not require any sophisticated equipment, involves safe and easy to handle reactants, has high efficiency, and low investment cost $[47,48]$. This review is focused on the wastewater treatment by CWPO using nano gold-based catalysts. The use of gold catalysts shown benefits as there is no loss of metal into solution and materials are stable and efficient, as will be further explained below.

\section{Catalytic Wet Peroxidation}

In the end of the 19th century, the CWPO process was firstly observed by H.J.H. Fenton, who described the highly oxidative properties of hydrogen peroxide in presence of iron ions during oxidation of tartaric acid [49]. Later, Haber and Weiss [27] discovered that the hydroxyl radical was the responsible for the degradation of the organic compounds. So, CWPO is based on the catalytic hydrogen peroxide decomposition by transition metallic cations $(\mathrm{M})$ that generates hydroxyl radicals (see Equation (5)) in mild reaction conditions [27,50-53]. In this process, the catalyst is oxidized in the reaction with $\mathrm{H}_{2} \mathrm{O}_{2}$, generating $\mathrm{HO}^{\bullet}$ (Equation (5)), being regenerated (reduced) with additional $\mathrm{H}_{2} \mathrm{O}_{2}$ molecules and even with the generated hydroperoxyl radicals $\left(\mathrm{HO}_{2}{ }^{\bullet}\right)$, according to Equations (6) and (7) [52-55].

$$
\begin{gathered}
\mathrm{M}^{\mathrm{n}+}+\mathrm{H}_{2} \mathrm{O}_{2} \rightarrow \mathrm{M}^{(\mathrm{n}+1)+}+\mathrm{HO}^{\bullet}+\mathrm{HO}^{-} \\
\mathrm{M}^{(\mathrm{n}+1)+}+\mathrm{H}_{2} \mathrm{O}_{2} \rightarrow \mathrm{M}^{\mathrm{n}+}+\mathrm{HO}_{2}^{\bullet}+\mathrm{H}^{+} \\
\mathrm{M}^{(\mathrm{n}+1)+}+\mathrm{HO}_{2}^{\bullet} \rightarrow \mathrm{M}^{\mathrm{n}+}+\mathrm{O}_{2}+\mathrm{H}^{+}
\end{gathered}
$$

The hydroxyl radical has an extremely short life-time but is very reactive as it can react with the excess of catalyst (Equation (8)) or even oxidant (Equation (9)) [50,52-55], being such reactions the undesired scavenging of the hydroxyl radicals.

$$
\begin{gathered}
\mathrm{M}^{\mathrm{n}+}+\mathrm{HO}^{\bullet} \rightarrow \mathrm{M}^{(\mathrm{n}+1)+}+\mathrm{HO}^{-} \\
\mathrm{H}_{2} \mathrm{O}_{2}+\mathrm{HO}^{\bullet} \rightarrow \mathrm{HO}_{2}^{\bullet}+\mathrm{H}_{2} \mathrm{O}
\end{gathered}
$$

The main limitations of homogeneous CWPO are the following: (i) the narrow $\mathrm{pH}$ range (2 to 4 ) in which the pollutants degradation efficiency is maximum $[52,55,56]$, and (ii) the need to recover the catalyst after treatment, in order to comply with environmental regulations, as shown by some authors [57]. A subsequent unit is required afterwards, in which the generated sludge, containing organic compounds as well as metals, has to be further treated, becoming the overall process more complex and expensive [48,52,54-56]. In order to overcome this challenge, several studies have been reported in literature dealing with supporting metals on solid porous matrices. By doing so, the metal is deposited on the support, becoming a heterogeneous catalyst, which is present in solution in a solid form, forming a slurry (batch reactors), being easily recovered; alternatively, it can be packed in a fixed bed reactor.

The principles of the heterogeneous process are very similar to the homogeneous; however, complexity increases due to the diffusion/adsorption phenomenon. It is widely accepted that hydrogen peroxide is adsorbed on the matrix pores, but this is not completely proved [58].

The main reactions of heterogeneous CWPO (Equations (10)-(14)) are the same as the homogeneous analogue, but with the addition of the support $(\mathrm{X})$ :

$$
\begin{gathered}
X-M^{\mathrm{n}+}+\mathrm{H}_{2} \mathrm{O}_{2} \rightarrow \mathrm{X}-\mathrm{M}^{(\mathrm{n}+1)+}+\mathrm{HO} \mathrm{HO}^{-} \\
\mathrm{X}-\mathrm{M}^{(\mathrm{n}+1)+}+\mathrm{H}_{2} \mathrm{O}_{2} \rightarrow \mathrm{X}-\mathrm{M}^{\mathrm{n}+}+\mathrm{HO}_{2}^{\bullet}+\mathrm{H}^{+} \\
X-\mathrm{M}^{(\mathrm{n}+1)+}+\mathrm{HO}_{2}^{\bullet} \rightarrow \mathrm{X}-\mathrm{M}^{\mathrm{n}+}+\mathrm{O}_{2}+\mathrm{H}^{+}
\end{gathered}
$$




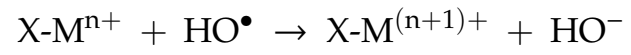

$$
\begin{aligned}
& \mathrm{H}_{2} \mathrm{O}_{2}+\mathrm{HO}^{\bullet} \rightarrow \mathrm{HO}_{2}^{\bullet}+\mathrm{H}_{2} \mathrm{O}
\end{aligned}
$$

The wastewater treatment by CWPO has been extensively studied for decades, mostly using supported iron as a catalyst $[29,52,58-61]$ (in this case, the process being called Fenton or Fenton-like). Recent studies report on catalysts where iron has been replaced by other metals, such as nickel, cobalt, copper, cerium, and manganese, as well as bimetallic particles [47,51,62-65]. However, quite often, such materials are not stable, leaching the metal to the effluent, making their reuse not possible, and their industrial application unfeasible.

In order to overcome the problem of the catalysts lack of stability, some authors report on effluents treated by CWPO using gold catalysts supported on porous matrices. Although this might seem less economically attractive, given the price of gold, these catalysts present high stability, with negligible metal leaching, and are efficient in hydrogen peroxide consumption and pollutants degradation [66-75]. In the next sections, we will discuss some methods of preparation of nano gold-based catalysts and the treatment of effluents by CWPO catalyzed by gold.

\section{Nano Gold-based Catalysts}

For gold to be an active catalyst, its synthesis must be carefully made in order to obtain well dispersed nanoparticles on the support. This preparation process of the gold catalysts starts by obtaining colloidal gold in suspension, by reducing $\mathrm{Au}^{3+}$ to $\mathrm{Au}^{0}[76,77]$, using different reducing agents (such as alcohols, ascorbic and citric acid, amines, citrate, hydrazines, and toluene) $[77,78]$. As atomic gold is formed and its concentration increases, the solution becomes saturated and the metal gradually precipitates and forms nanoparticles. Nanoparticle formation is promoted by the addition of stabilizers [76,77], like amines, quaternary alkyl ammonium ions, phosphine, carboxyl acids, and thiols [77].

Usually, gold colloids are obtained by applying the Turkevich method [79], which consists on the reaction between $\mathrm{AuCl}_{4}{ }^{-}$(using tetrachloroauric acid $\left(\mathrm{HAuCl}_{4}\right.$ ) or sodium tetrachloroauric $\left(\mathrm{NaAuCl}_{4}\right)$ ) with sodium citrate as reducing agent and capping [80], resulting in gold nanoparticles with particle diameters of 10-12 nm [76,77]. However, for catalytic purposes, it is advantageous that gold particles have smaller sizes, between 2 and $10 \mathrm{~nm}$ [77]. This is achieved by reducing $\mathrm{AuCl}_{4}{ }^{-}$with a strong reducing agent, such as $\mathrm{NaBH}_{4}[77,78]$.

Another method for generating gold colloids was developed by Brust et al. [76]. It is based in the reaction of $\mathrm{HAuCl}_{4}$ solution with $\mathrm{NaBH}_{4}$ (reducing agent), in the presence of toluene and tetraoctylammonium bromide (TOAB) which acts as a transfer cation, stabilizing agent, and anti-coagulant. First, the migration of $\mathrm{AuCl}_{4}{ }^{-}$from water to the organic phase (toluene) takes place, by ion metathesis of the counter anion on the phase transfer agent. Then, addition of sodium borohydride promotes the precursor reduction to metallic gold. This method produces gold nanoparticles with particle sizes between 2 to $6 \mathrm{~nm}[76,77]$.

The gold colloids can also be formed by dissolving $\mathrm{AuCl}_{4}{ }^{-}$in a solvent (like benzyl alcohol or ethylene glycol [78]), other than water. Reduction occurs by thermal treatment or addition of reducing agents [77].

The catalysts preparation is finalized by deposition of gold on a support (normally a metal oxide or a carbon material). Both processes (colloid formation and deposition on the support) can occur simultaneously and can be achieved by using several methods, namely deposition/precipitation (DP), co-precipitation $(\mathrm{CP})$, impregnation, vapor-phase deposition, grafting, sol-gel, ion-exchange, among others [80-83]. These most common techniques are described below.

\subsection{Deposition/Precipitation}

The DP method is one of the most widely used for gold catalysts preparation. This procedure was first described by Haruta [81], who adjusted the $\mathrm{pH}$ of $\mathrm{HAuCl}_{4}$ solution in the range 6-10 with $\mathrm{NaOH}$, 
then added the metal oxide used as support [80], and readjusted the $\mathrm{pH}$. The suspension was stirred during $1 \mathrm{~h}$ for gold precipitation in the form of $\mathrm{Au}(\mathrm{OH})_{3}$, that was deposited on the metal oxide surface. Finally, after the deposition step, the solid in suspension was recovered, washed, dried, and submitted to a thermal treatment at $250{ }^{\circ} \mathrm{C}$ in air atmosphere [81], or at $300{ }^{\circ} \mathrm{C}$ in hydrogen atmosphere [77], for gold reduction.

Haruta [81] referred the influence of $\mathrm{pH}$ on gold particle size. For $\mathrm{pH}$ about 6, the $\mathrm{AuCl}_{4}{ }^{-}$is transformed into $\left[\mathrm{Au}(\mathrm{OH})_{n} \mathrm{Cl}_{4-\mathrm{n}}\right]^{-}(\mathrm{n}=1$ to 3$)$ and the mean size of gold particles size is less than $4 \mathrm{~nm}$. For $\mathrm{pH}$ in the range 7 to 8 , the $\mathrm{n}$ value is close to 3 , which is preferable for the preparation of the gold catalysts, depending on the support. At lower $\mathrm{pH}$, the hydrolysis of the $\mathrm{Au}-\mathrm{Cl}$ bond takes place in a smaller extent. Moreover, for values of $\mathrm{pH}$ below the oxide isoelectric point, its surface is positively charged and consequently adsorbs more negative charged gold species. This results in a higher concentration of chloride on the surface, which promotes high mobility of gold, leading to the formation of larger particles [80]. For $\mathrm{pH}$ values above the isoelectric point of the support, the adsorption of negatively charged gold species decreases drastically. Consequently, the gold loading is lower, and so is the chloride concentration, with smaller particles of Au being formed [80]. Figure 2a shows a HR-TEM image and histogram of gold nanoparticle size distribution of a catalyst prepared at $\mathrm{pH} 9$ by deposition/precipitation. This procedure is reproducible, very reliable, and the obtained catalysts show high catalytic activity.
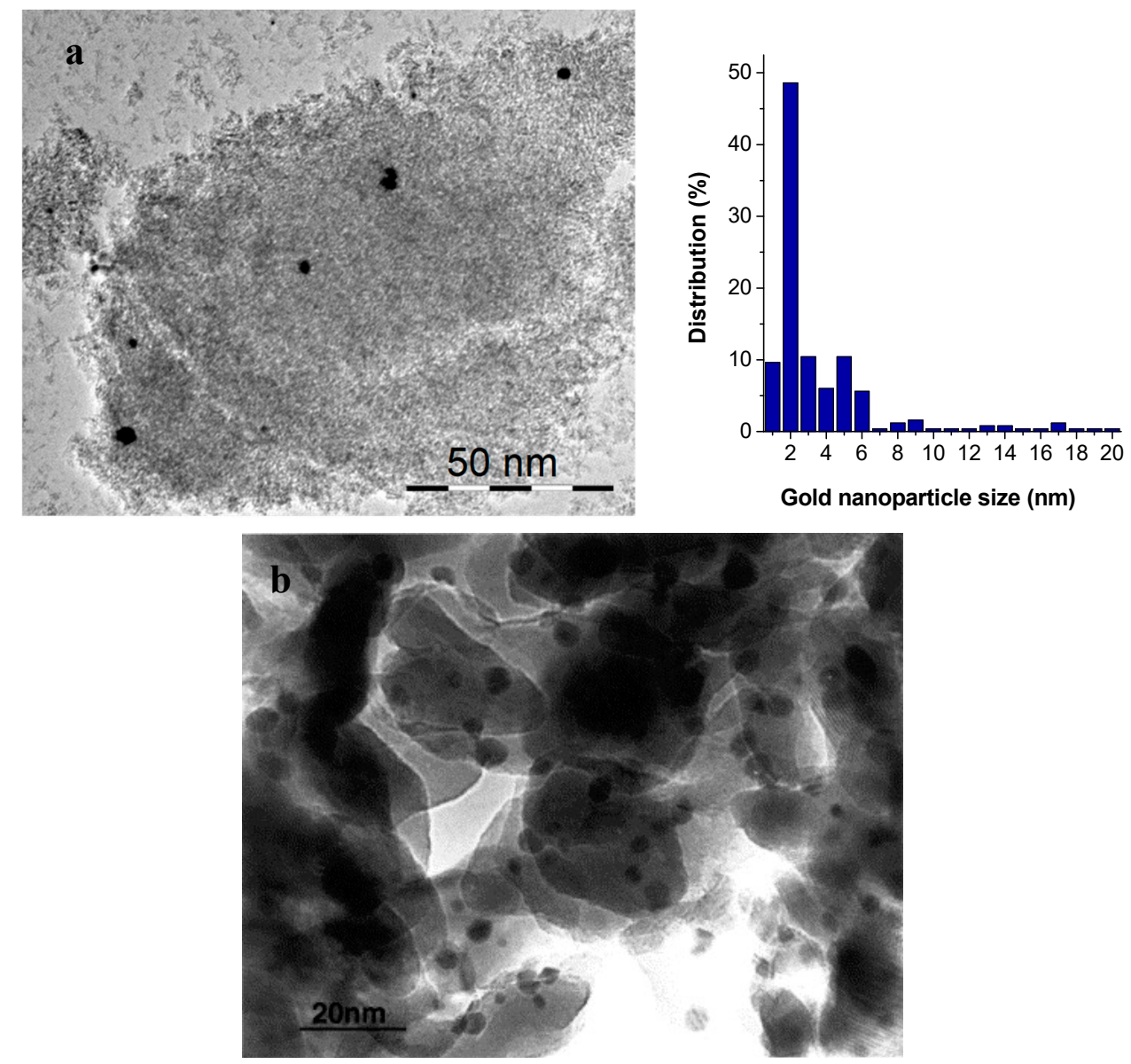

Figure 2. -HR-TEM image and histogram of gold particle size distribution of $\mathrm{Au} / \mathrm{Al}_{2} \mathrm{O}_{3}$ catalyst (a) prepared at $\mathrm{pH} 9.0$ by deposition/precipitation (DP) with $\mathrm{NaOH}$ and heating at $70{ }^{\circ} \mathrm{C}$ and -HR-TEM image of an $\mathrm{Au} / \alpha-\mathrm{Fe}_{2} \mathrm{O}_{3}$ catalyst (b) prepared by the co-precipitation method calcined at $400{ }^{\circ} \mathrm{C}$. Nanogold particles are seen as dark spots. Adapted from Rodrigues et al. [67] and Hodge et al. [84], respectively. 


\subsection{Co-Precipitation}

This method is based on simultaneous CP of hydroxide or carbonate and gold. For that, the gold precursor $\left(\mathrm{HAuCl}_{4}\right)$ and the soluble metal salt precursor (preferably a nitrate) are added to a $\mathrm{Na}_{2} \mathrm{CO}_{3}$ (and/or $\mathrm{NH}_{4} \mathrm{OH}$ ) solution and the suspension is mixed for a few minutes. After $1 \mathrm{~h}$ aging, the precipitates (Au and metal oxide) are washed and filtrated for five consecutive cycles, then dried overnight, and finally calcined in air atmosphere, to obtain a powder material $[80-82,85]$. This method differs from DP, in the sense that both oxide and gold are co-precipitated at the same time (in DP, Au is deposited on the already prepared support).

The preparation of catalysts by $\mathrm{CP}$ needs a concentration of metal salt around $0.1-0.4 \mathrm{M}, \mathrm{pH}$ range of 7-10 and temperature of precipitation and calcination between $47-87$ and $227-397^{\circ} \mathrm{C}$. Within these conditions, a homogeneous dispersion of gold nanoparticles can be obtained [82].

$\mathrm{CP}$ is the most useful and simple method; however, its applicability is limited, as only metal hydroxides or carbonates can be co-precipitated with $\mathrm{Au}(\mathrm{OH})_{3}$; moreover, reducible supports $\left(\alpha-\mathrm{Fe}_{2} \mathrm{O}_{3}\right.$, $\mathrm{CO}_{3} \mathrm{O}_{4}, \mathrm{NiO}$, and $\mathrm{ZnO}$ ) have to be employed in order to obtain a good dispersion of the gold nanoparticles $[80,82]$. Figure $2 \mathrm{~b}$ shows a HR-TEM image of a Au catalyst prepared by this method.

\subsection{Impregnation Method}

This method consists in impregnating the support with a gold salt solution. This may be done by suspending the support on a large volume of metal salt, from which the solvent is removed, or by filling the pores of the support with the solution (this later procedure being called incipient wetness impregnation). Then, the precursor is dried and calcined at temperatures as high as $800^{\circ} \mathrm{C}$ and reduced with hydrogen atmosphere at $120-250{ }^{\circ} \mathrm{C}$, or aqueous oxalic acid at $40^{\circ} \mathrm{C}$, or aqueous magnesium citrate $[80,83]$.

In the preparation of gold catalysts by this method, usually chloroauric acid $\left(\mathrm{HAuCl}_{4} \cdot 3 \mathrm{H}_{2} \mathrm{O}\right)$ or auric chloride $\left(\mathrm{AuCl}_{3}\right.$ or $\left.\mathrm{Au}_{2} \mathrm{Cl}_{6}\right)$ are used as metal precursors. However, complex salts such as potassium aurocyanide $\left(\mathrm{KAu}(\mathrm{CN})_{2}\right)$ and the ethylenediamine complex $\left[\mathrm{Au}(\mathrm{en})_{2}\right] \mathrm{Cl}_{3}$ may also be employed. Regarding the supports, silica, alumina, and magnesia are often used, but titanium oxide, boehmite $(\mathrm{AlO}(\mathrm{OH}))$, magnesium hydroxide, or ferric oxide $\left(\alpha-\mathrm{Fe}_{2} \mathrm{O}_{3}\right)$ have also be employed [83]. Figure 3 a shows a HR-TEM image of a $\mathrm{Au} / \mathrm{Al}_{2} \mathrm{O}_{3}$ catalyst prepared by incipient wetness impregnation.

Although impregnation is a classical procedure in the preparation of platinum group metal catalysts, it is not often applicable to gold, since the obtained catalysts show larger gold particle sizes when compared to materials prepared by CP or DP techniques. Moreover, they show low catalytic activity and it is difficult to obtain a good dispersion of the gold on the metal oxides. On one hand, gold has less affinity for these supports and lower melting point $\left(1063^{\circ} \mathrm{C}\right)$ than those of $\mathrm{Pd}\left(1550{ }^{\circ} \mathrm{C}\right)$ or $\mathrm{Pt}\left(1769^{\circ} \mathrm{C}\right)$. On the other hand, during calcination of the precursor at low temperature (below $600{ }^{\circ} \mathrm{C}$ ) the crystals of $\mathrm{HAuCl}_{4}$ are dispersed on the surface of the support and the chloride ion markedly enhances the coagulation of gold particles [80-82,86].

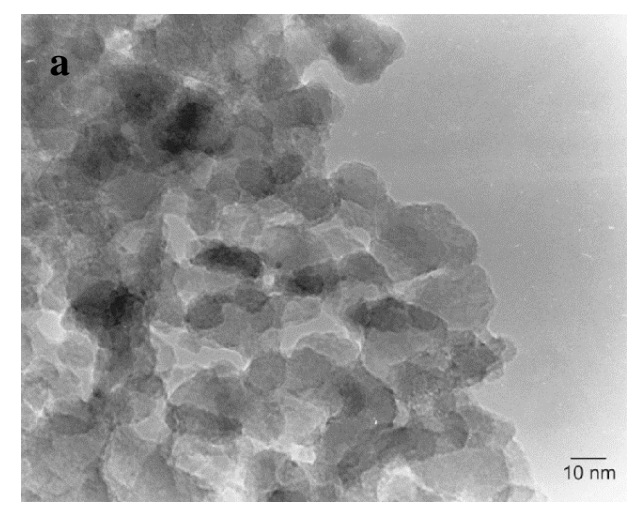

Figure 3. Cont. 

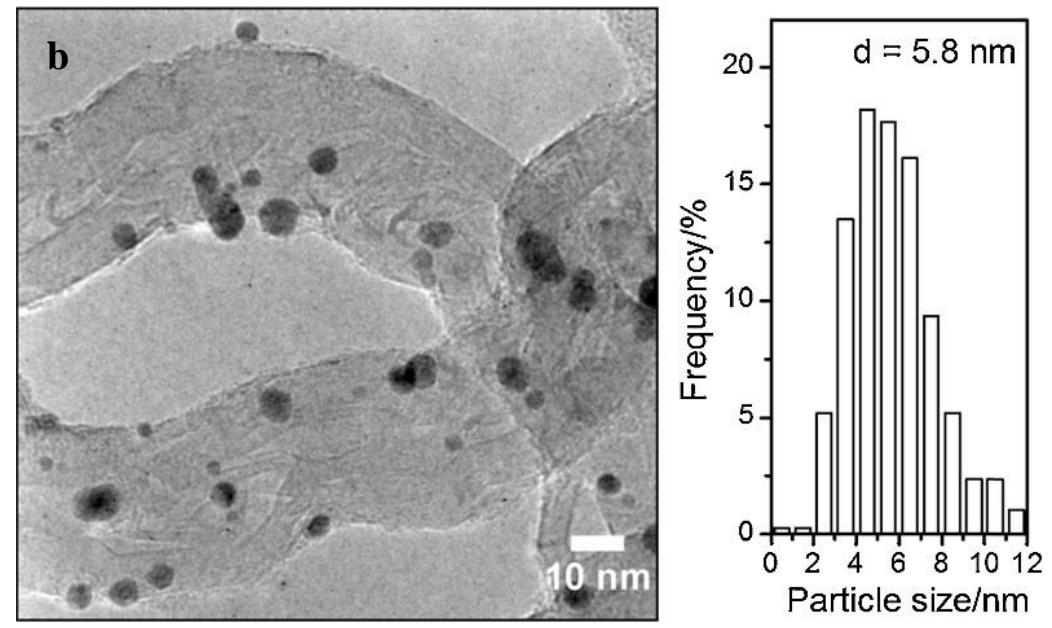

Figure 3. (a) $\mathrm{HR}$-TEM image of an $\mathrm{Au} / \mathrm{Al}_{2} \mathrm{O}_{3}$ catalyst prepared by incipient wetness impregnation, reduced at $250{ }^{\circ} \mathrm{C}$ using $5 \%$ (vol.) of hydrogen in nitrogen as gas phase. (b) HR-TEM image and respective histogram of gold particle size distribution of $\mathrm{Au} / \mathrm{CNT}$ prepared by vapor-phase deposition (dried overnight at $90{ }^{\circ} \mathrm{C}$ ). Gold nanoparticles are seen as dark spots. Adapted from Baatz et al. [87] and Lorençon et al. [88], respectively.

\subsection{Vapor-phase Deposition and Grafting Methods}

The procedures for preparation of gold-based catalysts by these two methods are similar, the only difference being in the use (or not) of solvent. In the vapor-phase deposition method (also called chemical vapor deposition), a vapor of an organic gold compound (such as dimethyl-gold(III)-acetyl acetone, dimethyl-gold(III) $\beta$-diketone, or gold acetylacetonate) is transported onto a high area support by an inert gas stream and chemically reacts with the support surface to form a precursor of gold. The organic gold compound adsorbed on the support is pyrolyzed in air atmosphere, to be decomposed into small gold particles $[80,81,83]$. This method can be applied to a variety of metal oxides, including acidic supports, like silica oxide $[80,81,83]$. Figure $3 \mathrm{~b}$ presents a HR-TEM image and histogram of particle size distribution of a gold catalyst supported on carbon nanotubes prepared by the vapor-phase deposition method.

In the grafting method, a gold complex $\left(\left[\mathrm{Au}\left(\mathrm{PPh}_{3}\right)\right] \mathrm{NO}_{3}\right.$ and/or $\left.\left[\mathrm{Au}_{9}\left(\mathrm{PPh}_{3}\right)_{8}\right]\left(\mathrm{NO}_{3}\right)_{3}\right)$ in solution is grafted onto the surface of a number of precipitated wet hydroxides (manganese and cobaltous hydroxides being particularly effective), which have many $\mathrm{OH}$ groups at the surface, which react with gold $[80,83]$. Then, drying in vacuum at room temperature and temperature-programmed calcination in air atmosphere are carried out, in order to cause a simultaneous transformation of the precursor to gold particles and oxides [80]. The deposition of gold on activated carbon is only achieved with the grafting method, however, the gold particles have too large diameters, around $10 \mathrm{~nm}$ [82], which leads to an inferior catalytic activity.

\subsection{Sol-Gel Method}

According to several authors, in the sol-gel method a sol solution of the support is obtained by mixing the support precursor (like tetra-ethyl-ortho-silicate, aluminum tri-sec-butoxide, aluminum isopropoxide, or tetrabutoxy-titanium) with water, ethanol and methanol, and/or nitric acid. Then, the gold precursor (such as chloroauric acid, gold acetate, or hydrogen tetranitratoaurate) is added to the sol solution of the support, stirring vigorously for a variable time until the gel begins to be formed. The obtained gel is dried during $12-24 \mathrm{~h}$ at a temperature about $100-200{ }^{\circ} \mathrm{C}$ and a calcination step follows [80].

The catalysts prepared by this method show gold nanoparticles with sizes below $6 \mathrm{~nm}$, involving materials resulting from soluble precursors which form three-dimensional networks with the addition 
of a base [80]. In Figure 4a it is possible to see a TEM image and gold particles size distribution of gold nanoparticles support on activated carbon prepared by the sol immobilization method.
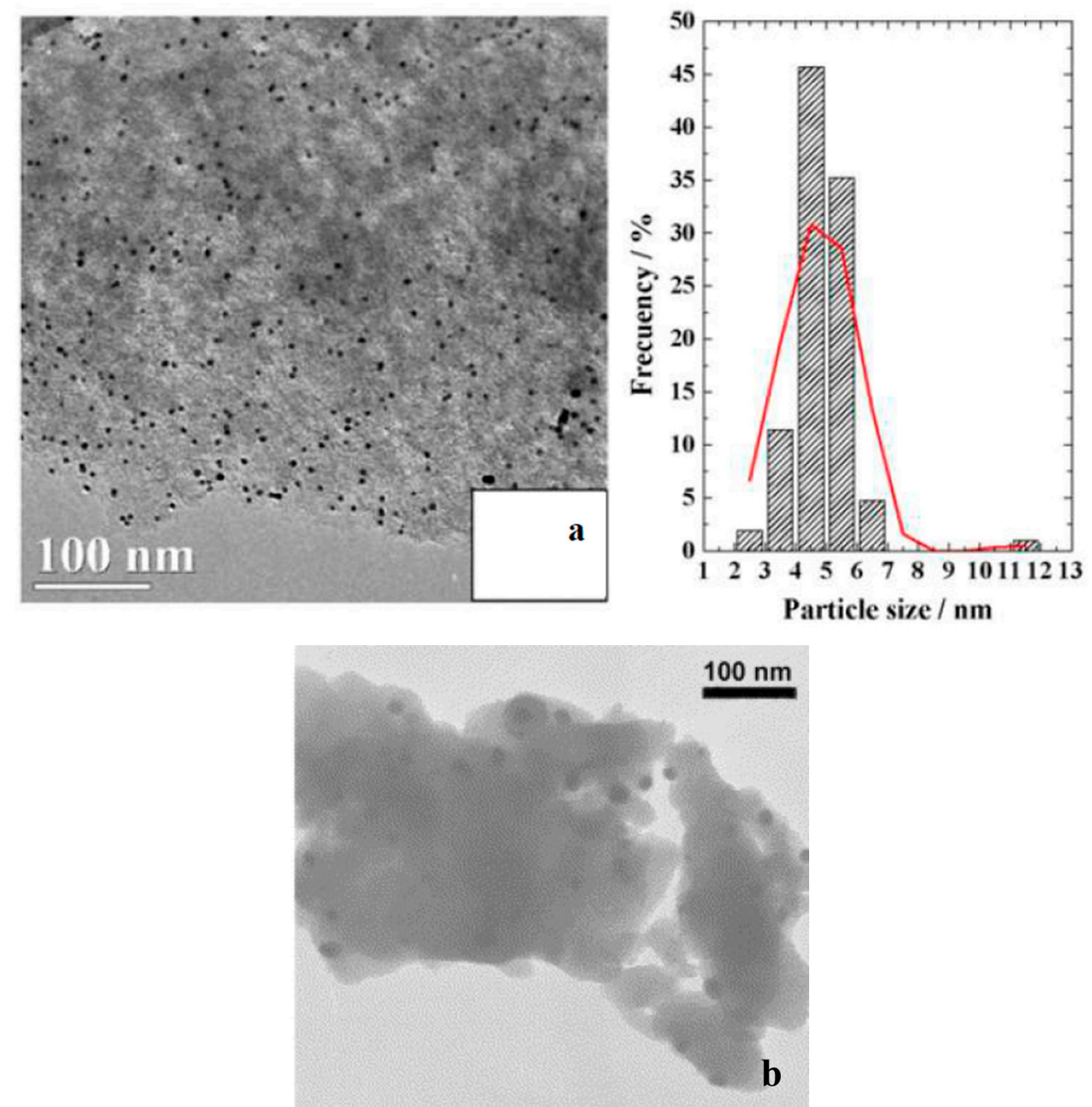

Figure 4. (a) TEM image and particle size distribution of $\mathrm{Au} / \mathrm{C}$ prepared by the sol immobilization method (dried at $60{ }^{\circ} \mathrm{C}$ until total evaporation of solution) and (b) TEM image of Au/Y prepared by ion-exchange at $25^{\circ} \mathrm{C}$ and $\mathrm{pH}=5.0$. Gold nanoparticles are seen as dark spots. Adapted from Quintanilla et al. [68] and Lin et al. [89], respectively.

\subsection{Ion-Exchange Method}

The ion-exchange method consists in replacing the protons or other cations on surface, or within the structure of the support, by gold, and this leads first to atomically dispersed species and then, after calcination and reduction with hydrogen, to small gold particles $[80,83]$.

This method is especially effective for depositing gold on zeolites, but the introduction of active species into the cavities of these supports, instead of placing gold on their external surface, presents several difficulties, for example, only limited cations or cationic complexes can be used $\left(\left[\mathrm{Au}(\mathrm{en})_{2}\right]^{3+}-\right.$ en = ethylenediamine - or $\left.\left[\mathrm{Au}\left(\mathrm{NH}_{3}\right)_{2}\right]^{+}\right)[80,83]$. For this reason, the ion-exchange method is rarely used in the preparation of gold catalysts, although small metal particles are obtained.

Figure $4 \mathrm{~b}$ shows a TEM image of gold supported on zeolite $(\mathrm{Au} / \mathrm{Y})$ catalyst prepared by the ion-exchange method.

In the next sections, we will present the treatment of wastewater by wet peroxidation using gold catalysts. The influence of catalyst properties and operating conditions, as well the catalyst stability, will be discussed. 


\section{Application of CWPO using Gold Catalysts in Wastewater Treatment}

In the last century, there was an increasing interest in the use of gold catalysts by the scientific community. These materials have been used in chemical and environmental catalysis, in reactions such as CO oxidation [85,90,91], hydrogenation [92], water-gas-shift [93-95], combustion of volatile organic compounds [96-98], and organic compounds reduction [99] or oxidation [86,100-102]. Gold catalysts have also been used in wastewater treatment by catalytic wet peroxidation, which is the focus of this review, as said above. Gold has replaced catalysts that, although being efficient in the removal of pollutants, present the disadvantage of high metal leaching, like iron-based catalysts $[69,70,103,104]$. Gold does not leach, is stable and efficient, as mentioned above and will be further discussed ahead.

The preparation methods previously described influence the gold particles size and, consequently, the dispersion of the metal on the surface of the support. These two parameters are correlated as demonstrated by Equation (15) and have a strong effect on the catalytic activity, as well as other properties of gold-based catalysts like pore size, surface area $\left(\mathrm{S}_{\mathrm{BET}}\right)$, mesoporosity of the support, and the oxidative state of gold.

Some authors correlate the effect of the gold amount and dispersion (and indirectly the particle size) with the catalytic performance, by evaluating the turnover frequency (TOF), which provides the number of molecules of target substrate degraded per gold atom and time unit (Equation (17)).

$$
\begin{gathered}
\mathrm{DM}(\%)=\frac{6 \times \mathrm{n}_{\mathrm{s}} \times \mathrm{MM} \times 1000}{\rho \times \mathrm{N} \times \mathrm{dp}} \times 100 \\
\mathrm{n}(\text { moles of gold })=\frac{\mathrm{Y}_{\mathrm{Au}} \times \mathrm{W}_{\text {cat }}}{\mathrm{MM}} \\
\operatorname{TOF}\left(\mathrm{h}^{-1}\right)=\frac{\mathrm{C}}{\frac{\mathrm{DM}}{100} \times \mathrm{n} \times \mathrm{t}}
\end{gathered}
$$

where: $C$ refers to the molecules of substrate degraded, $D M$ is the gold dispersion, $n$ is the number of moles of gold used, $t$ is the time of reaction, $n_{s}$ is the number of atoms at the surface per unit area $\left(1.15 \times 10^{19} \mathrm{~m}^{-2}\right.$ for Au) [105], MM is the molar mass of gold $(196.97 \mathrm{~g} / \mathrm{mol}), \rho$ is the density of gold $\left(19.5 \mathrm{~g} / \mathrm{cm}^{3}\right), N$ is the Avogadro's number $\left(6.022 \times 10^{23} \mathrm{~mol}^{-1}\right), d p$ is the average gold particle size $(\mathrm{nm})$, $Y_{A u}$ is the amount of gold in the catalyst (wt.\%), and $W_{c a t}$ is the mass of catalyst (g).

The efforts to achieve active and stable gold catalysts to be used in the treatment of effluents by CWPO, in view of industrial applications, have been reported in literature. Table 2 presents an outlook of the research made, showing which pollutants were degraded, the wastewater treatment conditions used, catalysts employed, and efficiency reached.

The efficiency of the catalytic wet peroxidation process for wastewater treatment is influenced by the catalyst properties and many operating conditions, such as gold loading, $\mathrm{pH}$, temperature, hydrogen peroxide dose, catalyst concentration, and also the radiation intensity source (the latter in the case of the photo-assisted wet peroxidation). The influence of the catalyst properties and the effect of such operating conditions, as well as the stability of these catalysts, will be briefly described below. 
Table 2. Gold catalyst used in CWPO of model compounds degradation or wastewater treatment, operational conditions, and performances reached.

\begin{tabular}{|c|c|c|c|c|}
\hline Model Compound/Effluent & Catalyst & Operation Conditions & Efficiency of CWPO & Ref. \\
\hline Orange II (OII) dye & $\mathrm{Au} / \mathrm{Al}_{2} \mathrm{O}_{3}(0.7$ wt.\%) & $\begin{array}{c}\mathrm{pH}=3.0 ; \mathrm{T}=50^{\circ} \mathrm{C} ;\left[\mathrm{H}_{2} \mathrm{O}_{2}\right]=6 \mathrm{mM} \\
{[\text { catalyst }]=2.0 \mathrm{~g} / \mathrm{L} ;[\mathrm{OII}]=0.1 \mathrm{mM}} \\
\mathrm{t}=4 \mathrm{~h}\end{array}$ & $\begin{array}{c}\text { Dye removal }=98.9 \% ; \mathrm{TOC} \text { removal }=49.8 \% \text {; COD } \\
\text { removal }=42.2 \% ; \mathrm{H}_{2} \mathrm{O}_{2} \text { consumption }=95.0 \% \text {; Specific } \\
\text { Oxygen Uptake Rate }=27.8 \mathrm{mgO}_{2} /\left(\mathrm{g}_{\mathrm{Vss}} . \mathrm{h}\right) ; \text { Inhibition of } \\
\text { Vibrio Fischeri }=0.0 \% \text {; Gold leaching }<0.04 \%\end{array}$ & [66] \\
\hline Acrylic Dyeing Wastewater & $\mathrm{Au} / \mathrm{Al}_{2} \mathrm{O}_{3}(0.7$ wt. $\%)$ & $\begin{aligned} \mathrm{pH}= & 3.0 ; \mathrm{T}=50^{\circ} \mathrm{C} ;\left[\mathrm{H}_{2} \mathrm{O}_{2}\right]=3.52 \mathrm{~g} / \mathrm{L} \\
& {[\text { catalyst }]=2.0 \mathrm{~g} / \mathrm{L} ; \mathrm{t}=4 \mathrm{~h} }\end{aligned}$ & $\begin{array}{c}\text { Color removal }=34.4 \% ; \text { TOC removal }=42.9 \% ; \mathrm{COD} \\
\text { removal }=50.5 \% ; \mathrm{H}_{2} \mathrm{O}_{2} \text { consumption }=98.8 \% \\
\mathrm{BOD}_{5}: \mathrm{COD}=0.23 ; \text { Gold leaching }<0.04 \%\end{array}$ & \\
\hline \multirow{5}{*}{ OII dye } & $\mathrm{Au} / \mathrm{Al}_{2} \mathrm{O}_{3}(0.7$ wt. $\%)$ & \multirow{5}{*}{$\begin{array}{c}\mathrm{pH}=3.0 ; \mathrm{T}=30^{\circ} \mathrm{C} ;\left[\mathrm{H}_{2} \mathrm{O}_{2}\right]=6 \mathrm{mM} \\
{[\text { catalyst }]=2.0 \mathrm{~g} / \mathrm{L} ;[\mathrm{OII}]=0.1 \mathrm{mM} ;} \\
\mathrm{t}=16 \mathrm{~h}\end{array}$} & $\begin{array}{l}\text { Dye removal }=99.4 \% ; \text { TOC removal }=48.2 \% ; \mathrm{H}_{2} \mathrm{O}_{2} \\
\text { consumption }=96.1 \% ; \text { Gold leaching }<0.04 \%\end{array}$ & \multirow{5}{*}[67]{} \\
\hline & $\mathrm{Au} / \mathrm{Fe}_{2} \mathrm{O}_{3}(0.8$ wt. $\%)$ & & $\begin{array}{l}\text { Dye removal }=51.4 \% ; \text { TOC removal }=36.9 \% ; \mathrm{H}_{2} \mathrm{O}_{2} \\
\quad \text { consumption }=68.5 \% ; \text { Gold leaching }<0.04 \%\end{array}$ & \\
\hline & $\mathrm{Au} / \mathrm{Fe}_{2} \mathrm{O}_{3}(4.0 \mathrm{wt} . \%)$ from WGC & & $\begin{array}{c}\text { Dye removal }=40.9 \% ; \text { TOC removal }=29.6 \% ; \\
\text { Gold leaching }<0.04 \%\end{array}$ & \\
\hline & $\mathrm{Au} / \mathrm{TiO}_{2}(1.6$ wt. $\%)$ & & $\begin{array}{l}\text { Dye removal }=68.9 \% ; \text { TOC removal }=32.4 \% ; \mathrm{H}_{2} \mathrm{O}_{2} \\
\text { consumption }=91.7 \% ; \text { Gold leaching }<0.04 \%\end{array}$ & \\
\hline & $\mathrm{Au} / \mathrm{ZnO}(1.2$ wt.\%) & & $\begin{array}{l}\text { Dye removal }=62.6 \% ; \mathrm{TOC} \text { removal }=31.9 \% ; \mathrm{H}_{2} \mathrm{O}_{2} \\
\quad \text { consumption }=96.1 \% ; \text { Gold leaching }<0.04 \%\end{array}$ & \\
\hline \multirow{5}{*}{ Phenol } & $\mathrm{Au} / \mathrm{TiO}_{2}(0.8$ wt. $\%)$ & \multirow{5}{*}{$\begin{array}{c}\text { [phenol] }=5.0 \mathrm{~g} / \mathrm{L} ; \text { [catalyst }]=2.7 \mathrm{~g} / \mathrm{L} ; \\
\mathrm{V}_{\mathrm{H} 2 \mathrm{O} 2}=5 \mathrm{~mL} ; \mathrm{t}=24 \mathrm{~h} \\
\mathrm{~V}_{\text {solution }}=45 \mathrm{~mL}\end{array}$} & $\begin{aligned} & \mathrm{TOF}_{\text {phenol }}= 0.07^{*} 10^{6}\left(\mathrm{~h}^{-1}\right) ; \mathrm{TOF}_{\mathrm{TOC}}=0.07^{*} 10^{6}\left(\mathrm{~h}^{-1}\right) \\
& \mathrm{TOF}_{\mathrm{H} 2 \mathrm{O} 2}=2.52^{*} 10^{6}\left(\mathrm{~h}^{-1}\right)\end{aligned}$ & \multirow{5}{*}[68]{} \\
\hline & $\mathrm{Au}(3) / \mathrm{C}(0.5$ wt. $\%)$ & & $\begin{aligned} \mathrm{TOF}_{\text {phenol }}= & 1.19^{*} 10^{6}\left(\mathrm{~h}^{-1}\right) ; \mathrm{TOF}_{\mathrm{TOC}}=1.08^{*} 10^{6}\left(\mathrm{~h}^{-1}\right) ; \\
& \mathrm{TOF}_{\mathrm{H} 2 \mathrm{O} 2}=16.70^{*} 10^{6}\left(\mathrm{~h}^{-1}\right)\end{aligned}$ & \\
\hline & $\mathrm{Au}(5) / \mathrm{C}(0.5$ wt. $\%)$ & & $\begin{aligned} \mathrm{TOF}_{\text {phenol }}= & 0.32^{*} 10^{6}\left(\mathrm{~h}^{-1}\right) ; \mathrm{TOF}_{\mathrm{TOC}}=0.25^{*} 10^{6}\left(\mathrm{~h}^{-1}\right) ; \\
& \mathrm{TOF}_{\mathrm{H} 2 \mathrm{O} 2}=4.07^{*} 10^{6}\left(\mathrm{~h}^{-1}\right)\end{aligned}$ & \\
\hline & $\mathrm{Au}(7) / \mathrm{C}(0.5$ wt. $\%)$ & & $\begin{aligned} & \mathrm{TOF}_{\text {phenol }}= 0.25^{*} 10^{6}\left(\mathrm{~h}^{-1}\right) ; \mathrm{TOF}_{\mathrm{TOC}}=0.25^{*} 10^{6}\left(\mathrm{~h}^{-1}\right) \\
& \mathrm{TOF}_{\mathrm{H} 2 \mathrm{O} 2}=2.27^{*} 10^{6}\left(\mathrm{~h}^{-1}\right)\end{aligned}$ & \\
\hline & $\mathrm{Au}(10) / \mathrm{C}(0.5$ wt.\%) & & $\begin{aligned} \text { TOF }_{\text {phenol }}= & 0.47^{*} 10^{6}\left(\mathrm{~h}^{-1}\right) ; \mathrm{TOF}_{\mathrm{TOC}}=0.43^{*} 10^{6}\left(\mathrm{~h}^{-1}\right) \\
& \mathrm{TOF}_{\mathrm{H} 2 \mathrm{O} 2}=1.87^{*} 10^{6}\left(\mathrm{~h}^{-1}\right)\end{aligned}$ & \\
\hline Phenol & $\mathrm{Au} / \mathrm{Hap}(2.4 \mathrm{wt} . \%$ of $\mathrm{Au})$ & $\begin{array}{c}\mathrm{pH}=2.0 ; \mathrm{T}=70^{\circ} \mathrm{C} \\
\mathrm{V}_{\mathrm{H} 2 \mathrm{O} 2 \text { with } 30 \mathrm{wt} . \%}=1 \mathrm{~mL} \\
\text { [catalyst }=0.1 \mathrm{~g} / \mathrm{L} ; \\
\text { [phenol] }=100 \mathrm{mg} / \mathrm{L} ; \mathrm{t}=2 \mathrm{~h}\end{array}$ & Phenol removal $=\sim 92.5 \%$ & {$[70]$} \\
\hline
\end{tabular}


Table 2. Cont

\begin{tabular}{|c|c|c|c|c|}
\hline Model Compound/Effluent & Catalyst & Operation Conditions & Efficiency of CWPO & Ref. \\
\hline \multirow{2}{*}{ Phenol } & $\mathrm{Au} / \mathrm{TiO}_{2}-\mathrm{AD}(2.8$ wt. $\%)$ & \multirow{2}{*}{$\begin{array}{c}{[\text { phenol }]=200 \mathrm{mg} / \mathrm{L}} \\
{\left[\mathrm{H}_{2} \mathrm{O}_{2}\right]=1520 \mathrm{mg} / \mathrm{L} ; \mathrm{pH}=2.5} \\
\mathrm{~T}=80^{\circ} \mathrm{C} ; \mathrm{P}=1 \mathrm{~atm} ; \mathrm{LHSV}=3.8 \mathrm{~h}^{-1}\end{array}$} & $\begin{array}{c}\text { Phenol removal }_{\text {steady-state }}=100.0 \% ; \text { TOC removal } \\
\text { steady-state }=\sim 65.0 \%\end{array}$ & \multirow{2}{*}{ [71] } \\
\hline & $\mathrm{Au} / \mathrm{TiO}_{2}-\mathrm{AD}(3.2$ wt. $\%)$ & & $\begin{aligned} \text { Phenol removal }_{\text {steady-state }} & =100.0 \% ; \text { TOC removal } \\
\text { steady-state } & =\sim 80.0 \%\end{aligned}$ & \\
\hline Phenol & $\mathrm{Au} / \mathrm{AC}(0.8 \mathrm{wt} . \%$ of $\mathrm{Au})$ & $\begin{array}{c}\mathrm{pH}=3.5 ; \mathrm{T}=80{ }^{\circ} \mathrm{C} ;\left[\mathrm{H}_{2} \mathrm{O}_{2}\right]=25 \mathrm{~g} / \mathrm{L} \\
{[\text { catalyst }]=2.5 \mathrm{~g} / \mathrm{L} ;[\mathrm{phenol}]=5 \mathrm{~g} / \mathrm{L}} \\
\mathrm{t}=22 \mathrm{~h}\end{array}$ & Phenol removal $=100 \%$; TOC removal $=70 \%$ & {$[72]$} \\
\hline Phenol & $\mathrm{Au} / \mathrm{DNP}(1 \mathrm{wt} . \%$ of $\mathrm{Au})$ & $\begin{array}{c}\mathrm{pH}=4.0 ; \mathrm{T}=50^{\circ} \mathrm{C} ;\left[\mathrm{H}_{2} \mathrm{O}_{2}\right]=1.44 \mathrm{~g} / \mathrm{L} ; \\
{[\text { catalyst }]=320 \mathrm{mg} / \mathrm{L}} \\
\text { [phenol] }=1 \mathrm{~g} / \mathrm{L} ; \mathrm{t}=7 \mathrm{~h}\end{array}$ & $\begin{aligned} \text { Phenol removal } & =100 \% ; \mathrm{H}_{2} \mathrm{O}_{2} \text { consumption }=100 \% ; \\
& \mathrm{BOD}_{5}: \mathrm{COD}=0.72\end{aligned}$ & {$[73]$} \\
\hline \multirow{6}{*}{ Phenol } & $\mathrm{Au} / \mathrm{CeO}_{2}(1.0 \%)$ & \multirow{6}{*}{$\begin{array}{c}\mathrm{pH}=4.0 ; \text { Room temperature; } \\
{\left[\mathrm{H}_{2} \mathrm{O}_{2}\right]=200 \mathrm{mg} / \mathrm{L}} \\
{[\mathrm{Au}]=0.0025 \mathrm{mM}} \\
{[\text { phenol }]=100 \mathrm{mg} / \mathrm{L} ; \mathrm{t}=24 \mathrm{~h}}\end{array}$} & $\begin{array}{c}\text { Phenol removal }=7.0 \% ; \mathrm{H}_{2} \mathrm{O}_{2} \text { consumption }=88.0 \% ; \text { Gold } \\
\text { leaching }=0.8 \%\end{array}$ & \multirow{6}{*}{ [74] } \\
\hline & $\mathrm{Au} / \mathrm{Fe}_{2} \mathrm{O}_{3}(1.5 \%)$ & & $\begin{array}{c}\text { Phenol removal }=3.0 \% ; \mathrm{H}_{2} \mathrm{O}_{2} \text { consumption }=8.0 \% ; \text { Gold } \\
\text { leaching }=0.7 \%\end{array}$ & \\
\hline & $\mathrm{Au} / \mathrm{TiO}_{2}(1.5 \%)$ & & $\begin{array}{c}\text { Phenol removal }=3.0 \% ; \mathrm{H}_{2} \mathrm{O}_{2} \text { consumption }=19.0 \% ; \text { Gold } \\
\text { leaching }=0.5 \%\end{array}$ & \\
\hline & $\mathrm{Au} / \mathrm{C}(0.8 \%)$ & & $\begin{array}{c}\text { Phenol removal }=7.0 \% ; \mathrm{H}_{2} \mathrm{O}_{2} \text { consumption }=14.0 \% ; \text { Gold } \\
\text { leaching }=5.8 \%\end{array}$ & \\
\hline & $\mathrm{Au} / \mathrm{npD}(<1.0 \%)$ & & $\begin{array}{c}\text { Phenol removal }<1.0 \% ; \mathrm{H}_{2} \mathrm{O}_{2} \text { consumption }=6.0 \% \text {; Gold } \\
\text { leaching }=0.5 \%\end{array}$ & \\
\hline & $\mathrm{Au} / \mathrm{HO}-\mathrm{npD}(1.0 \%)$ & & $\begin{array}{c}\text { Phenol removal }=93.0 \% ; \mathrm{H}_{2} \mathrm{O}_{2} \text { consumption }=48.0 \% \text {; Gold } \\
\text { leaching }=0.7 \%\end{array}$ & \\
\hline Methyl Blue dye (MB) & $\mathrm{Au} / \mathrm{CNT}$ (41.0 wt.\%) & $\begin{array}{c}{[\mathrm{MB} \text { dye }]=50 \mathrm{mg} / \mathrm{L}} \\
{[\text { catalyst }]=0.5 \mathrm{~g} / \mathrm{L} ;\left[\mathrm{H}_{2} \mathrm{O}_{2}\right]=500 \mathrm{mM}} \\
\mathrm{pH}=7.08 ; \mathrm{t}=120 \mathrm{~min}\end{array}$ & MB removal $=\sim 100 \%$ & \multirow[b]{2}{*}[88]{} \\
\hline $\begin{array}{l}\text { 1,1-diphenyl-2-picrylhydrazyl } \\
\text { (DPPH) }\end{array}$ & $\begin{array}{c}\mathrm{Au} / \mathrm{CNT} \text { placed in } \\
\text { water/cyclohexane mixture }(1 / 10 \\
\mathrm{v} / \mathrm{v})(41.0 \text { wt. } \%)\end{array}$ & $\begin{array}{l}{[\mathrm{DPPH}]=0.2 \mathrm{mM} ;[\text { catalyst }]=1 \mathrm{~g} / \mathrm{L}} \\
{\left[\mathrm{H}_{2} \mathrm{O}_{2}\right]=250 \mathrm{mM} ; \mathrm{t}=10 \mathrm{~min} ; \text { Room }} \\
\text { temperature; } \mathrm{W} / \mathrm{O}=1: 10 \mathrm{v} / \mathrm{v}\end{array}$ & DPPH removal = $100 \%$ & \\
\hline Acid Orange 7 (AO7) dye & $\mathrm{Au} / \mathrm{CeO}_{2}(1 \mathrm{wt} . \%$ of $\mathrm{Au})$ & $\begin{array}{c}{\left[\mathrm{H}_{2} \mathrm{O}_{2}\right]=20 \mathrm{mM} ;[\text { catalyst }]=0.5 \mathrm{~g} / \mathrm{L}} \\
{[\text { dye }]=35 \mathrm{mg} / \mathrm{L} ; \mathrm{t}=33 \mathrm{~h}}\end{array}$ & $\mathrm{AO} 7 \mathrm{removal}=80 \%$ & [106] \\
\hline
\end{tabular}


Table 2. Cont

\begin{tabular}{|c|c|c|c|c|}
\hline Model Compound/Effluent & Catalyst & Operation Conditions & Efficiency of CWPO & Ref. \\
\hline Methyl Orange dye (MO) & $\mathrm{Au} / \mathrm{TN}(1.0 \mathrm{wt} . \%)$ & $\begin{array}{c}[\mathrm{MO}]=50 \mathrm{mg} / \mathrm{L} ; \text { [catalyst }]=2 \mathrm{~g} / \mathrm{L} \\
{\left[\mathrm{H}_{2} \mathrm{O}_{2}\right]=0.15 \mathrm{M} ; \mathrm{pH}=3.0 ; \mathrm{T}=80^{\circ} \mathrm{C}} \\
\mathrm{t}=240 \mathrm{~min}\end{array}$ & $\mathrm{MO}$ removal $=85 \% ; \mathrm{TOC}$ removal $=83 \%$ & {$[107]$} \\
\hline \multirow{9}{*}{ Bisphenol A (BPA) } & $\mathrm{Au} / \mathrm{SRAC}(3.0 \mathrm{wt} . \%)$ & \multirow{8}{*}{$\begin{array}{c}{[\mathrm{BPA}]=114 \mathrm{mg} / \mathrm{L} ;} \\
{[\text { catalyst }]=125 \mathrm{mg} / \mathrm{L} ;} \\
{\left[\mathrm{H}_{2} \mathrm{O}_{2}\right]=530 \mathrm{mg} / \mathrm{L} ; \mathrm{pH}=3.0 ;} \\
\mathrm{T}=30^{\circ} \mathrm{C}\end{array}$} & BPA removal $=89.0 \% ; \mathrm{H}_{2} \mathrm{O}_{2}$ consumption $=44.1 \%$ & \multirow{9}{*}[108]{} \\
\hline & $\mathrm{Au} / \mathrm{PSAC}(3.0 \mathrm{wt} . \%)$ & & BPA removal $=23.8 \% ; \mathrm{H}_{2} \mathrm{O}_{2}$ consumption $=8.3 \%$ & \\
\hline & $\mathrm{Au} / \mathrm{CNF}(3.0$ wt. $\%)$ & & BPA removal $=20.4 \% ; \mathrm{H}_{2} \mathrm{O}_{2}$ consumption $=14.5 \%$ & \\
\hline & $\mathrm{Au} / \mathrm{FDU}-15$ (3.0 wt.\%) & & BPA removal $=32.4 \% ; \mathrm{H}_{2} \mathrm{O}_{2}$ consumption $=22.8 \%$ & \\
\hline & $\mathrm{Au} / \mathrm{X} 40 \mathrm{~s}(10.0 \mathrm{wt} \%)$ & & BPA removal $=14.5 \% ; \mathrm{H}_{2} \mathrm{O}_{2}$ consumption $=10.7 \%$ & \\
\hline & $\mathrm{Au} / \mathrm{Fe}_{2} \mathrm{O}_{3}(5.0$ wt. $\%)$ & & BPA removal $=10.1 \% ; \mathrm{H}_{2} \mathrm{O}_{2}$ consumption $=7.6 \%$ & \\
\hline & $\mathrm{Au} / \mathrm{TiO}_{2}(1.5$ wt. $\%)$ & & BPA removal $=5.3 \% ; \mathrm{H}_{2} \mathrm{O}_{2}$ consumption $=10.8 \%$ & \\
\hline & $\mathrm{Au}-\mathrm{Fe}_{2} \mathrm{O}_{3} / \mathrm{Al}_{2} \mathrm{O}_{3}(0.5$ wt. $\%)$ & & BPA removal $=6.6 \% ; \mathrm{H}_{2} \mathrm{O}_{2}$ consumption $=15.3 \%$ & \\
\hline & $\mathrm{Au} / \mathrm{SRAC}(1.5$ wt.\%) & $\begin{array}{c}{[\mathrm{BPA}]=89 \mathrm{mg} / \mathrm{L}} \\
{[\text { catalyst }]=125 \mathrm{mg} / \mathrm{L}} \\
{\left[\mathrm{H}_{2} \mathrm{O}_{2}\right]=530 \mathrm{mg} / \mathrm{L} ; \mathrm{pH}=3.0} \\
\mathrm{~T}=30^{\circ} \mathrm{C}\end{array}$ & $\mathrm{BPA}$ removal $=\sim 80.0 \% ; \mathrm{H}_{2} \mathrm{O}_{2}$ consumption $=\sim 40.0 \%$ & \\
\hline
\end{tabular}

$*$ TOF $=$ turnover frequency 


\subsection{Influence of the Catalyst Properties}

As already mentioned above, the catalytic properties directly affect the efficiency of the CPWO process. Ge et al. [106] concluded that the textural properties influenced AO7 dye removal, and achieved $80 \%$ for $\mathrm{Au} / \mathrm{CeO}_{2}$ with a lower $\mathrm{S}_{\mathrm{BET}}\left(55 \mathrm{~m}^{2} / \mathrm{g}\right)$ and an intermediate gold content $(1 \mathrm{wt} . \%)$.

Alvaro et al. [109] concluded that the morphological properties of gold supported on mesoporous titania had an influence in the decontamination of Soman wastewater. The authors reached the best decontamination degree $(\sim 100 \%)$ for a catalyst with medium surface area $\left(90 \mathrm{~m}^{2} / \mathrm{g}\right)$ and large pore diameter $(7.1 \mathrm{~nm})$ associated to a highest gold loading $(0.70 \mathrm{wt} . \%)$, among the studied samples.

Navalon et al. [74] evaluated phenol oxidation by CWPO using gold supported on $\mathrm{CeO}_{2}, \mathrm{TiO}_{2}$, carbon, $\mathrm{Fe}_{2} \mathrm{O}_{3}, \mathrm{npD}$, and $\mathrm{HO}-\mathrm{npD}$, and observed that catalysts with smaller gold particle size $(<1 \mathrm{~nm})$ and intermediate gold loading $(1.0 \%)$ led to the highest performance (total phenol disappearance and $48.0 \%$ of hydrogen peroxide consumption). Moreover, a small amount of gold $(0.7 \%)$ was leached from the support to the solution.

However, in the three studies reported above, the authors do not indicate any explanation why the efficiency of CPWO was the best for the catalysts selected. The main characteristics influencing the catalysts performance in CPWO are morphology and porosity (adsorption capacity), gold loading, and particle size.

The optimization of the gold loading of a catalyst is essential for economic aspects, as mentioned above, and is determinant for catalysing the reaction that generates hydroxyl radicals, influencing the efficiency of CWPO. In the work of Rodrigues et al. [67], the efficiency of CWPO decayed dramatically when the loading of gold on iron oxide increased from 0.8 to $4.0 \mathrm{wt} . \%$, reducing from 99.7 to $36.6 \%$ and from 75.8 to $24.0 \%$ for OII dye and TOC removals, respectively. Moreover, a significant reduction was observed in the production of hydroxyl radicals with increasing gold content.

However, in a work using CWPO assisted with radiation to treat an OII dye solution with gold on iron oxide, the gold content had no effect on the colour removal [110]. This is due to the fact that the dye is degraded in the presence of UV/vis radiation alone. However, the authors observed a slight reduction in mineralization from 68.2 to $58.4 \%$ when the gold content increased, as well as in the production of hydroxyl radicals [110].

In both studies mentioned above, the authors pointed out an explanation for the decay of the process performance with the increase of the gold content; if in excess, gold reacts with the hydroxyl radical $\left(\mathrm{HO}^{\bullet}+\mathrm{Fe}_{2} \mathrm{O}_{3}-\mathrm{Au}^{0} \rightarrow \mathrm{Fe}_{2} \mathrm{O}_{3}-\mathrm{Au}^{+}+\mathrm{HO}^{-}\right)$, being less available to oxidize the dye, and the reaction by-products $[66,110]$.

The degradation of methyl orange decreased from $\sim 40$ to $\sim 10 \%$ when the gold loading increased from 1.0 to $4.0 \mathrm{wt} . \%$, in a study dealing with the removal of this dye by CWPO, at $25^{\circ} \mathrm{C}$, using gold supported on modified titanium nanotubes [107]. The authors attributed this decreased of process efficiency to the fact that the catalyst with lower gold content had a smaller particle size and gold was uniformly distributed on the surface of the support [107].

On the other hand, and as shown in Figure 5a, the degradation of AO7 dye increased with gold loading until $1 \mathrm{wt} . \%$; however, a further increase of catalyst content to $2 \mathrm{wt} . \%$ impaired the oxidation of the dye by CWPO, using gold on cerium oxide as catalyst [106], increasing the ratio between the AO7 concentration after $30 \mathrm{~h}$ of reaction $(\mathrm{C})$ and the initial AO7 concentration $\left(\mathrm{C}_{0}\right), \mathrm{C} / \mathrm{C}_{0}$, from 0.2 to 0.4. Furthermore, the combination of CWPO with visible radiation showed an optimum for $1 \mathrm{wt} . \%$ of gold loading for shorter reaction times (less than $5 \mathrm{~h}$ ), more notorious in the period from 2 to $5 \mathrm{~h}$ (see Figure 5b) [106].

In contrast with the above-mentioned studies that showed the existence of an optimal gold loading, Yang et al. [108] observed that the removal of bisphenol A and consumption of hydrogen peroxide increased from 21.1 and $9 \%$ to 89.0 and $45 \%$, respectively, after $12 \mathrm{~h}$ of reaction, when the gold content in an $\mathrm{Au} / \mathrm{AC}$ catalyst increased from 0 to $3 \mathrm{wt} . \%$. Moreover, Sempere et al. [75] observed a decrease in the turnover frequency (calculated according to Equations (15)-(17)) of phenol and hydrogen peroxide from $\sim 100$ and $320 \mathrm{~h}^{-1}$ to $\sim 70$ and $180 \mathrm{~h}^{-1}$, respectively, when the gold loading increased from 0.1 
to $0.5 \mathrm{wt} . \%$ in $\mathrm{Au} / \mathrm{FH}_{2}$, and subsequent annealing treatment with hydrogen for sunlight assisted CWPO. The authors pointed out an explanation for the decay of the catalytic activity with increasing particle size, i.e., the catalyst having a lower gold content had a smaller particle diameter and showed more efficiency.

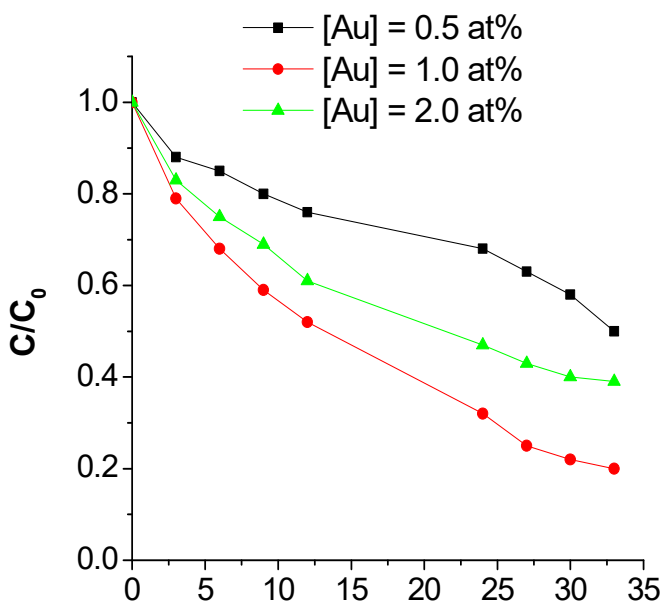

$\mathbf{t}(\mathrm{h})$

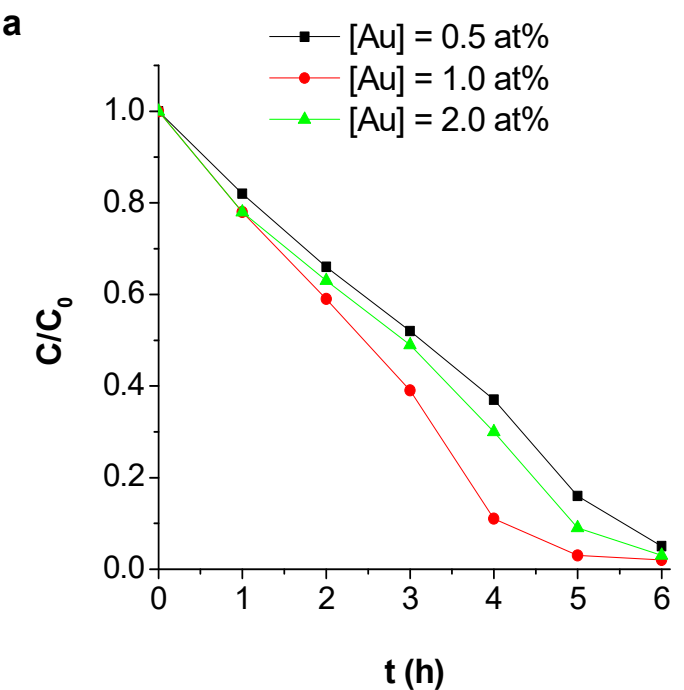

$\mathbf{t}(\mathbf{h})$

Figure 5. $\mathrm{C} / \mathrm{C}_{\mathrm{o}}$ ratio during $\mathrm{AO} 7$ degradation by $\mathrm{CWPO}(\mathbf{a})$ and assisted with visible radiation (b) processes at different gold loadings $([\mathrm{AO}]]=35 \mathrm{mg} / \mathrm{L},\left[\mathrm{H}_{2} \mathrm{O}_{2}\right]=20 \mathrm{mM}$ and $\left.\left[\mathrm{Au} / \mathrm{CeO}_{2}\right]=0.5 \mathrm{~g} / \mathrm{L}\right)$. Adapted from Ge et al. [106].

The studies described above allow us to conclude that the effect of the gold loading in the efficiency of CPWO depends on the type of catalyst used and the compound/wastewater to be treated.

Quintanilla et al. [68] evaluated the degradation of phenol, the mineralization and $\mathrm{H}_{2} \mathrm{O}_{2}$ consumption by wet peroxidation using $\mathrm{Au} / \mathrm{C}, \mathrm{Au} / \mathrm{Fe}_{2} \mathrm{O}_{3}$, and $\mathrm{Au} / \mathrm{TiO} \mathrm{O}_{2}$. They verified that activated carbon is the preferable support because it has a higher adsorption capacity. Also, $\mathrm{Au} / \mathrm{C}$ with less amount of gold $(0.13 \mathrm{wt} . \%)$, lower gold size $(5.1 \mathrm{~nm})$, and higher fraction of $\mathrm{Au}^{\delta+}$ in the catalyst surface $(31 \%)$, presented the highest TOF for phenol oxidation $\left(1.19 \times 10^{4} \mathrm{~h}^{-1}\right)$, TOC reduction $\left(1.08 \times 10^{4} \mathrm{~h}^{-1}\right)$, and $\mathrm{H}_{2} \mathrm{O}_{2}$ consumption $\left(16.70 \times 10^{4} \mathrm{~h}^{-1}\right)$, see Table 3. This catalyst $(\mathrm{Au}(3) / \mathrm{C})$ had gold particles with about $5 \mathrm{~nm}$ size, which is beneficial for the catalytic performance.

Table 3. Gold loading, particle size and percentage of exposed surface gold species of the catalysts, and turnover frequency (TOF) values of phenol, TOC oxidation, and hydrogen peroxide decomposition (experimental conditions: [Phenol] $=5 \mathrm{~g} / \mathrm{L}$, [Catalyst] $=2.7 \mathrm{~g} / \mathrm{L}, \mathrm{V}_{\mathrm{H} 2 \mathrm{O} 2}=5 \mathrm{~mL}, \mathrm{t}=24 \mathrm{~h}$ and $\mathrm{V}_{\text {solution }}=45 \mathrm{~mL}$ ). Adapted from Quintanilla et al. [68].

\begin{tabular}{cccccccc}
\hline Catalyst & $\begin{array}{c}{[\mathbf{A u}]_{\text {total }}} \\
(\mathbf{w t .} \%)\end{array}$ & $\begin{array}{c}\mathbf{A u}^{\mathbf{0}} \text { Fraction } \\
\mathbf{( \% )}\end{array}$ & $\begin{array}{c}\mathbf{A u}^{\delta+} \text { Fraction } \\
\mathbf{( \% )}\end{array}$ & \multicolumn{2}{c}{ Au Size } & \multicolumn{2}{c}{ TOF $\times \mathbf{1 0}^{-\mathbf{4}} \mathbf{( h}^{-\mathbf{1}} \mathbf{)}$} \\
$\mathbf{( n m )}$ & Phenol & TOC & $\mathbf{H}_{\mathbf{2}} \mathbf{O}_{\mathbf{2}}$ \\
\hline $\mathrm{Au} / \mathrm{TiO}_{2}$ & 0.80 & 79 & 21 & $3.1 \pm 1.8$ & 0.07 & 0.07 & 2.52 \\
$\mathrm{Au}(3) / \mathrm{AC}^{*}$ & 0.13 & 69 & 31 & $5.1 \pm 2.0$ & 1.19 & 1.08 & 16.70 \\
$\mathrm{Au}(5) / \mathrm{AC}^{*}$ & 0.47 & 72 & 28 & $4.9 \pm 1.0$ & 0.32 & 0.25 & 4.07 \\
$\mathrm{Au}(7) / \mathrm{AC}^{*}$ & 0.48 & 71 & 29 & $6.8 \pm 1.7$ & 0.25 & 0.25 & 2.27 \\
$\mathrm{Au}(10) / \mathrm{AC}^{*}$ & 0.50 & 69 & 31 & $9.1 \pm 1.1$ & 0.47 & 0.43 & 1.87 \\
\hline
\end{tabular}

* The numbers correspond to the initial average size $(\mathrm{nm})$ of gold in the colloidal solution used for the catalyst preparation.

Rodrigues et al. [67] tested gold supported on titanium, zinc, aluminum, and iron oxides to treat a dye solution by CWPO. They concluded that the $\mathrm{Au} / \mathrm{Al}_{2} \mathrm{O}_{3}$ catalyst with higher surface area $\left(\mathrm{S}_{\mathrm{BET}}=210 \mathrm{~m}^{2} / \mathrm{g}\right)$, lower amount of gold $(0.7 \mathrm{wt} . \%)$, and an intermediate gold particle size $(3.6 \mathrm{~nm})$, had the best performance (removal of dye and TOC of ca. $98 \%$ and $47 \%$, respectively, consumption of 
$\mathrm{H}_{2} \mathrm{O}_{2} \sim 96 \%$, and higher hydroxyl radicals generation) and the highest TOF value for OII dye removal $\left(75.5 \times 10^{-6} \mathrm{~s}^{-1}\right)$. The best efficiency of $\mathrm{CPWO}$ for $\mathrm{Au} / \mathrm{Al}_{2} \mathrm{O}_{3}$ was associated to its higher adsorption capacity. The same was concluded for these same catalysts when light-assisted CWPO was used for OII dye degradation [110]. $\mathrm{Au} / \mathrm{Al}_{2} \mathrm{O}_{3}$ permitted total discoloration and TOC removal of about $80 \%$, combining further formation of hydroxyl radicals [110]. In the same way, Drašinac et al. [107] observed that the morphological properties of the catalysts and gold properties played an important role in methyl orange (MO) dye degradation. These authors reached the best CPWO performance (removals of 83 and $85 \%$ for TOC and MO dye, respectively) with gold supported on modified titanium nanotubes with a gold nanoparticle size of $7 \mathrm{~nm}$ and $1.1 \mathrm{wt} . \%$ loading, which had the highest total pore volume $\left(1.31 \mathrm{~cm}^{3} / \mathrm{g}\right)$, pore diameter $(14.8 \mathrm{~nm})$, and surface area $\left(335 \mathrm{~m}^{2} / \mathrm{g}\right)$. The authors reported that, in addition to the low gold content in the catalyst, the smaller particle diameter and the uniform distribution on the surface of the support benefit the catalytic process.

Yang et al. [108] reached the best performance of CWPO (89.0 and 44.1\% for bisphenol A (BPA) removal and oxidant conversion, respectively) using a gold supported on styrene-based activated carbon $(\mathrm{Au} / \mathrm{SRAC})$ catalyst, wcih had an intermediate gold nanoparticle size $(4.4 \mathrm{~nm})$ and loading (3.0 wt.\%). The authors pointed out the small gold size of the material as being beneficial in the degradation of the compound and oxidant conversion. On the other hand, Han et al. [70] reached the maximum removal of phenol $(82 \%)$ and space-time conversion $\left(0.53 \mathrm{mmol} \mathrm{h}^{-1} \mathrm{~L}^{-1}\right)$ when using a gold supported on hydroxyapatite (Au/Hap) catalyst with higher gold particle size $(4.9 \mathrm{~nm})$ and intermediate loading $(2.4 \mathrm{wt} . \%)$. The authors stated that the best catalytic activity of this sample was due to the gold particle size close to $5 \mathrm{~nm}$.

These studies showed that the textural properties of the catalysts, as well as the gold particle size, play an important role in the efficiency of the catalytic process.

\subsection{Effect of the Operating Conditions}

The efficiency of the catalytic wet peroxidation process for wastewater treatment is also influenced by many operating conditions, such as catalyst dose, $\mathrm{pH}$, temperature, hydrogen peroxide concentration, and also the radiation intensity source (the latter in the case of the photo-assisted wet peroxidation). The effect of such operating conditions will be briefly described below.

\subsubsection{Catalyst Dose}

The efficiency of the process increases with the catalyst concentration, since more gold will be available in the reaction medium to catalyze CWPO, generating more hydroxyl radicals. However, above a certain concentration of catalyst there is very often a negative effect, once scavenging of hydroxyl radicals by the excess of gold occurs (Equation (13)). The ideal concentration of catalyst depends on the type of effluent to treat, being necessary to optimize it. In the work developed by Domínguez et al. [72], a linear increasing dependence was obtained for initial reaction rates of phenol and oxidant disappearance for a $\mathrm{Au} / \mathrm{AC}$ concentration in the range of $0-6 \mathrm{~g} / \mathrm{L}$.

As reported by Domínguez et al. [72], the work of Martín et al. [73] showed that an increase in the $\mathrm{Au} / \mathrm{DNP}$ catalyst concentration from 50 to $320 \mathrm{mg} / \mathrm{L}$ proportionately increased the initial reaction rate of phenol degradation and oxidant consumption (see Figure 6). The same tendency was observed by Navalon et al. [111], as the initial phenol degradation and $\mathrm{H}_{2} \mathrm{O}_{2}$ decomposition rates increased for $\mathrm{Au} / \mathrm{HO}-\mathrm{npD}$ concentrations, in the range of 0 to $400 \mathrm{mg} / \mathrm{L}$, for solar light assisted CWPO.

On the other hand, Rodrigues et al. [66] reached an optimum dose of $\mathrm{Au} / \mathrm{Al}_{2} \mathrm{O}_{3}$ catalyst of $2.0 \mathrm{~g} / \mathrm{L}$ that maximized the OII degradation and mineralization, as well as the formation of hydroxyl radicals (see Figure 7) when CWPO was applied to the dye solution. Moreover, the oxidant decomposition increased with catalyst dose until $2.0 \mathrm{~g} / \mathrm{L}$, but remained equal for the highest concentration tested (see Figure 7a). No gold leaching was found in any of the tests. 


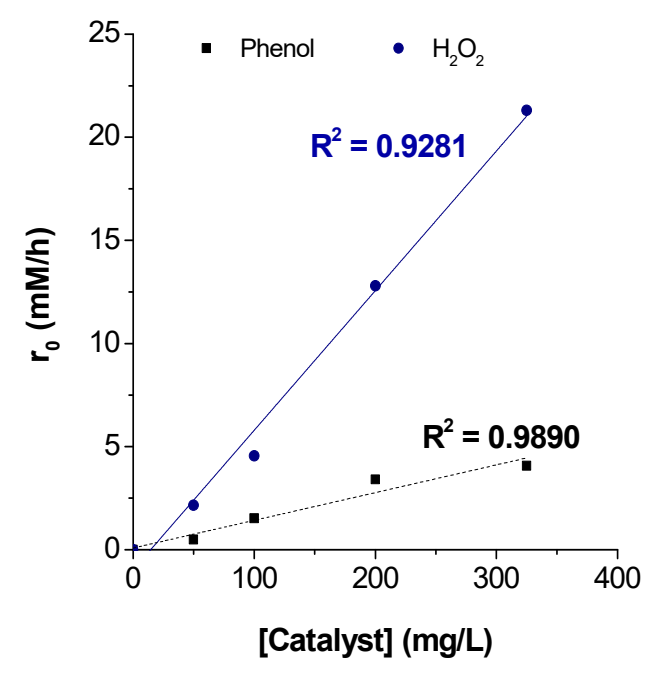

Figure 6. Effect of catalyst dose on the initial reaction rate of phenol oxidation and oxidant decomposition $\left([\text { phenol }]_{\text {initial }}=1.0 \mathrm{~g} / \mathrm{L},\left[\mathrm{H}_{2} \mathrm{O}_{2}\right]_{\text {initial }}=1.44 \mathrm{~g} / \mathrm{L}, \mathrm{T}=50{ }^{\circ} \mathrm{C}\right.$ and $\left.\mathrm{pH}_{\text {initial }}=4.0\right)$. Adapted from Martín et al. [73].
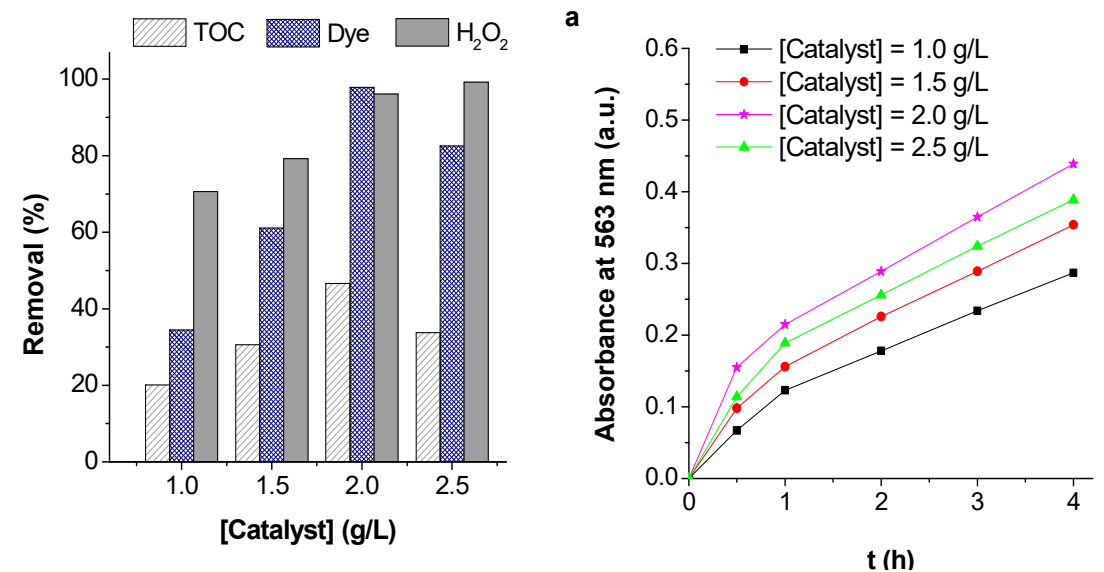

Figure 7. Influence of catalyst concentration in orange II dye and TOC removals and $\mathrm{H}_{2} \mathrm{O}_{2}$ consumption after $4 \mathrm{~h}(\mathbf{a})$ and evolution of hydroxyl radical formation $(\mathbf{b})\left([\mathrm{OII}]_{\mathrm{a}}\right)=0.1 \mathrm{mM}$ or $\left.[\mathrm{OII}]_{\mathrm{b}}\right)=0.0 \mathrm{mM}$, $\left[\mathrm{H}_{2} \mathrm{O}_{2}\right]=6.0 \mathrm{mM}, \mathrm{T}=30{ }^{\circ} \mathrm{C}$ and $\mathrm{pH}_{\text {initial }}=3.0$ ). Adapted from Rodrigues et al. [66].

Similarly to what was reported earlier by Rodrigues et al. [66], in a subsequent work of the same authors [110], the effect of $\mathrm{Au} / \mathrm{Al}_{2} \mathrm{O}_{3}$ concentration in OII oxidation by CWPO assisted by UV/visible radiation was evaluated. The maximum dye and TOC removals were achieved for a dose of $2.0 \mathrm{~g} / \mathrm{L}$, being 96.8 and $85.9 \%$, respectively, after $2 \mathrm{~h}$ of reaction. The oxidant consumption increased with catalyst dose in the range of 1.0 to $2.5 \mathrm{~g} / \mathrm{L}$. Furthermore, for all catalyst doses, no gold leaching was found.

For an industrial application of CWPO in the treatment of effluents, the optimization of the catalyst concentration is crucial, not only for the efficiency of the process, but also in economic aspects. So, it is necessary to use the lowest catalyst quantity in order to reduce the costs of the treatment process, since gold catalysts are expensive, compared to other catalysts containing iron, copper, and others.

\subsubsection{Hydrogen Peroxide Concentration}

The initial concentration of $\mathrm{H}_{2} \mathrm{O}_{2}$ also plays a very important role in the oxidation of organic compounds in CWPO processes and in the operating costs of such treatment procedures; thus, it is necessary to determine the optimum dose of this reagent. 
The improvement of the process by the addition of $\mathrm{H}_{2} \mathrm{O}_{2}$ is mostly due to the increased production of hydroxyl radicals, as described in Equations (10), (11), and (20). However, at high peroxide concentrations, the reaction between excess $\mathrm{H}_{2} \mathrm{O}_{2}$ and the strong oxidant $\mathrm{HO}$ ' species becomes more relevant and, as a consequence, no subsequent improvement on the heterogeneous CWPO rate can be noticed, as the produced $\mathrm{HO}_{2}{ }^{\bullet}$ radicals are less reactive than the $\mathrm{HO}^{\bullet}$ radicals (Equation (14)) [112]. Contrarily, if the concentration is low, the oxidation degree is small and there is the possibility of formation of unwanted intermediate products, which, in most cases, are more toxic and less biodegradable than the original compounds. Inherently, it is common to observe the existence of an optimum oxidant (hydrogen peroxide) dose in either wet peroxidation or radiation-assisted wet peroxidation processes.

The existence of an optimum oxidant dose was reported by several authors for CWPO catalyzed by gold on different supports [66,88,108,110,111]. In the work developed by Rodrigues et al. [66], the effect of this parameter was evaluated in the range of 3.0 to $12.0 \mathrm{mM}$. An increase in the removal of dye and TOC was observed, as well as in the formation of hydroxyl radicals with hydrogen peroxide concentration until $6.0 \mathrm{mM}$, but the efficiency of the process was reduced for higher oxidant doses (see Figure 8). The consumption of $\mathrm{H}_{2} \mathrm{O}_{2}$ also increased until $6 \mathrm{mM}$ and remained constant for the higher doses. The authors reached 46.6 and $97.8 \%$ of TOC and dye removals, respectively, and $\sim 100 \%$ for hydrogen peroxide consumption after $4 \mathrm{~h}$ of reaction with the optimized oxidant dose.
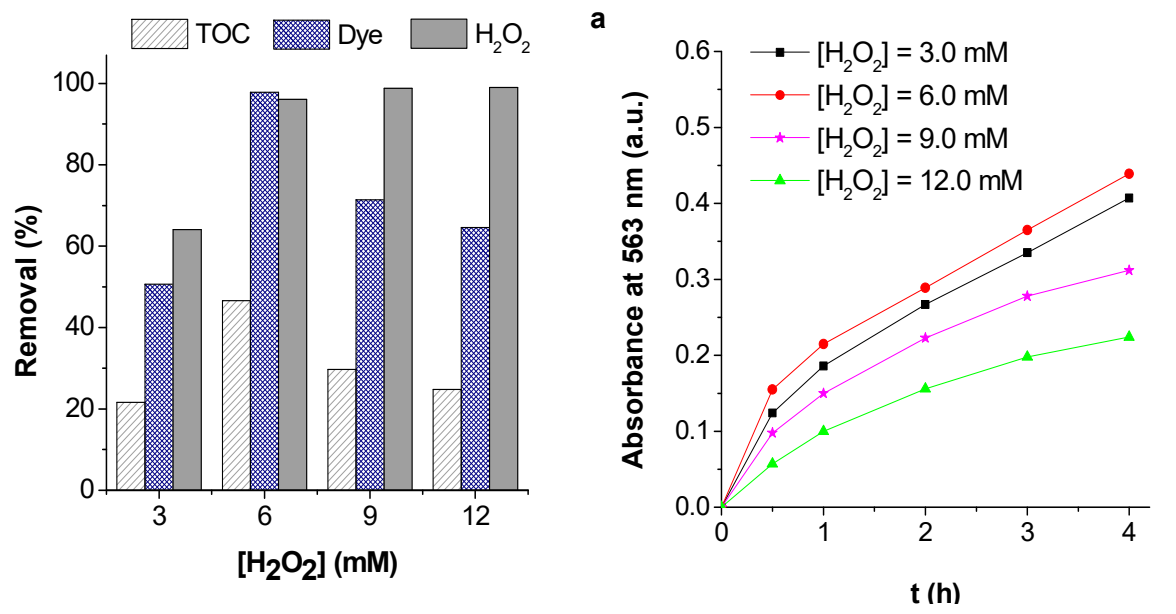

Figure 8. Effect of hydrogen peroxide concentration in dye and TOC removals and hydrogen peroxide consumption after $4 \mathrm{~h}$ of reaction (a) and hydroxyl radicals formation during CWPO (b) for a $\mathrm{Au} / \mathrm{Al}_{2} \mathrm{O}_{3}$ catalyst $\left([\mathrm{OII}]_{\mathrm{a})}=0.1 \mathrm{mM}\right.$ or $[\mathrm{OII}]_{\mathrm{b})}=0.0 \mathrm{mM}$, [catalyst $]=2.0 \mathrm{~g} / \mathrm{L}, \mathrm{T}=30^{\circ} \mathrm{C}$ and $\left.\mathrm{pH}_{\text {initial }}=3.0\right)$. Adapted from Rodrigues et al. [66].

Another study evaluated the degradation of OII dye by photo-assisted CWPO, and the reduction of color, mineralization, and oxidant consumption increased when the oxidant dose increased from 1.5 to $3.0 \mathrm{mM}$ [110]; for concentrations of 6.0 and $12.0 \mathrm{mM}$, a negative effect was observed for dye and TOC removals. For the optimal oxidant concentrations, efficiencies of $85.9,96.8$, and $94.5 \%$ were reached for dye and TOC removals and $\mathrm{H}_{2} \mathrm{O}_{2}$ consumption, respectively. Moreover, authors reported that the catalyst used (gold on alumina) did not show any leaching for any of the concentrations of hydrogen peroxide evaluated.

Yang et al. [108] tested gold supported on carbon as a CWPO catalyst for the oxidation of BPA. A smaller oxidant dose $(275 \mathrm{mg} / \mathrm{L})$ allowed to remove $~ 50 \%$ of the model compound and ca. $35 \%$ of oxidant consumption was found after $12 \mathrm{~h}$ of reaction. An improvement of catalytic activity was observed when the hydrogen peroxide concentration was increased to $530 \mathrm{mg} / \mathrm{L}$, allowing, after $12 \mathrm{~h}$, to reach a bisphenol A reduction of ca. $70 \%$ and a consumption of oxidant of about $40 \%$. However, a further increase in the oxidant dosage $(835 \mathrm{mg} / \mathrm{L})$ did not influence the efficiency of CWPO. A similar 
tendency was reported by Lorençon et al. [88] for the CWPO catalyzed with $\mathrm{Au} / \mathrm{CNT}$ for the degradation of a lipophilic compound (DPPH). The removal of DPPH increased with $\mathrm{H}_{2} \mathrm{O}_{2}$ concentration until $250 \mathrm{mM}$ and remained practically constant for higher oxidant doses, as shown in Figure 9. The authors attained total degradation of DPPH for an optimal oxidant concentration of $250 \mathrm{mM}$. These two works highlighted once again the existence of an optimum oxidant dose for the gold catalysed CWPO process.

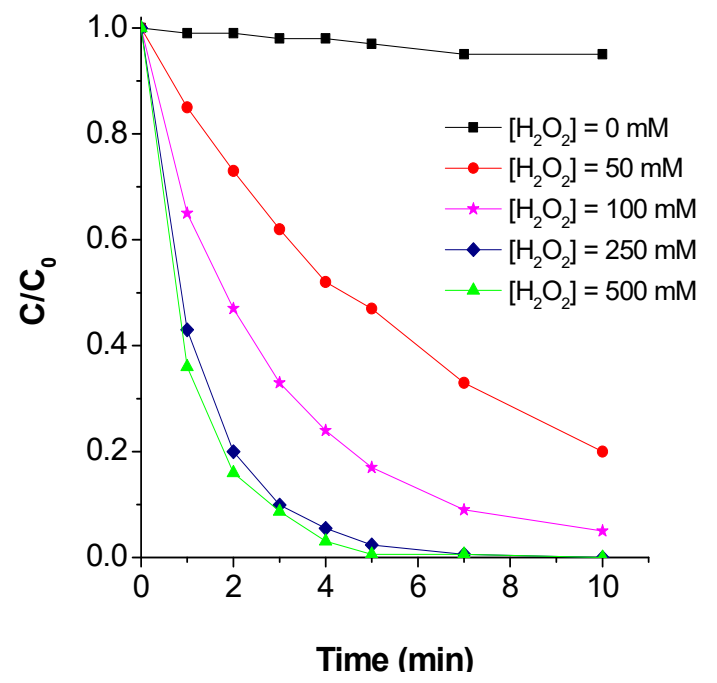

Figure 9. Influence of initial hydrogen peroxide concentration in the degradation of a lipophilic compound $(\mathrm{DPPH})$ by CWPO using $\mathrm{Au} / \mathrm{CNT}$ as catalyst $\left([\mathrm{DPPH}]_{0}=0.2 \mathrm{mM}\right.$, [catalyst $]=1.0 \mathrm{mg} / \mathrm{mL}$, $\mathrm{T}=$ room temperature, stirring $=600 \mathrm{rpm}$ ). Adapted from Lorençon et al. [88].

Contrarily to what was reported in the studies mentioned above, in which an optimum oxidant dose was found, in the work of Martín et al. [73] a reduction in the concentration (or even up to total absence) of phenol and intermediate compounds (catechol, quinone, and hydroquinone) was found, resulting from the oxidation of the pollutant when the $\mathrm{H}_{2} \mathrm{O}_{2}$ concentration was increased in the tested range (362-1447 $\mathrm{mg} / \mathrm{L})$. On the other hand, the biodegradability of the effluent improved, increasing the $\mathrm{BOD}_{5}: \mathrm{COD}$ ratio from $~ 0.05$ to 0.4 , when the oxidant dose increased from 362 to $1447 \mathrm{mg} / \mathrm{L}$. However, higher doses were not tested.

The optimization of hydrogen peroxide amount is not only important for economic reasons, as the reagent is relatively expensive, but also to guarantee that $\mathrm{H}_{2} \mathrm{O}_{2}$ solution is not in excess. On one hand, too much $\mathrm{H}_{2} \mathrm{O}_{2}$ is detrimental to the subsequent biological treatment, if required, having deleterious effects on the microorganisms and leadingto a decrease in the efficiency of the biological process. On the other hand, an excess of $\mathrm{H}_{2} \mathrm{O}_{2}$ contributes to the COD of the treated effluent, a commonly legislated parameter, and can give an erroneous indication of the possibility of the effluent discharge into water bodies.

\subsubsection{Initial $\mathrm{pH}$}

The efficiency of wet peroxidation is also strongly dependent on the $\mathrm{pH}$ of the medium. $\mathrm{A} \mathrm{pH}<2.5$ allows the scavenging reaction between the hydroxyl radical and $\mathrm{H}^{+}$to take place (Equation (18)) [113]. Furthermore, at neutral or alkaline conditions, hydrogen peroxide self-decomposition into water and oxygen (Equation (19)) is promoted, decreasing the amount of available oxidant to yield hydroxyl radicals to promote organics degradation.

$$
\begin{gathered}
\mathrm{H}^{+}+\mathrm{HO}^{\bullet}+\mathrm{e}^{-} \rightarrow \mathrm{H}_{2} \mathrm{O} \\
2 \mathrm{H}_{2} \mathrm{O}_{2} \rightarrow 2 \mathrm{H}_{2} \mathrm{O}+\mathrm{O}_{2}
\end{gathered}
$$


In the homogeneous process, for very acidic $\mathrm{pH}$ values, $\mathrm{Au}^{+}$is present in lesser amounts, while higher $\mathrm{pHs}$ lead to precipitation of gold in insoluble form (AuHO), resulting in reduction of the amount of Au available, which leads to small formation of radicals (Equation (5)). These drawbacks are overcome when gold is supported on a porous support (heterogeneous process), once the metal is inside the pores and confined within the structure of the solid matrix $[52,114]$. This reduces the precipitation of gold that occurs in the homogeneous process; thus, the catalyst is available to decompose the hydrogen peroxide and generate the hydroxyl radical.

However, Domínguez et al. [72] observed that the CWPO of phenol using gold supported on activated carbon was efficient in acid and neutral $\mathrm{pH}$ range (3.5-7.5) and decreased significantly for $\mathrm{pH}=10.5$. The authors achieved, after $24 \mathrm{~h}$ of reaction, removals of phenol and TOC of $\sim 100$ and $\sim 60 \%$, respectively, with an efficiency of hydrogen peroxide use ( $\eta$, evaluated by the ratio between the amount of TOC removal and oxidant consumption) of 0.8 for $\mathrm{pH}$ values between 3.5 to 7.5.

A similar behavior was found by Martín et al. [73]. These authors showed that gold supported on diamond nanoparticles was catalytically active in the $\mathrm{pH}$ range between 4 and 7 , with almost all phenol being degraded. They also observed a strong decay in its removal for the $\mathrm{pH}$ of 8 and 9 and total consumption of hydrogen peroxide for all values of $\mathrm{pH}$ tested (Figure 10). These authors reported that the biodegradability (evaluated by the $\mathrm{BOD}_{5}: \mathrm{COD}$ ratio) was higher $(\sim 0.7)$ for the lower $\mathrm{pH}$ value tested (4.0), which was associated with no phenol detection and the lowest concentration of catechol and hydroquinone (intermediate compounds resulting from the oxidation of phenol) after CWPO treatment at this $\mathrm{pH}$ value, and decreased to values near 0.4 for higher $\mathrm{pHs}(5.0-7.0)$ that present phenol and higher concentrations of catechol and hydroquinone in solution after treatment.
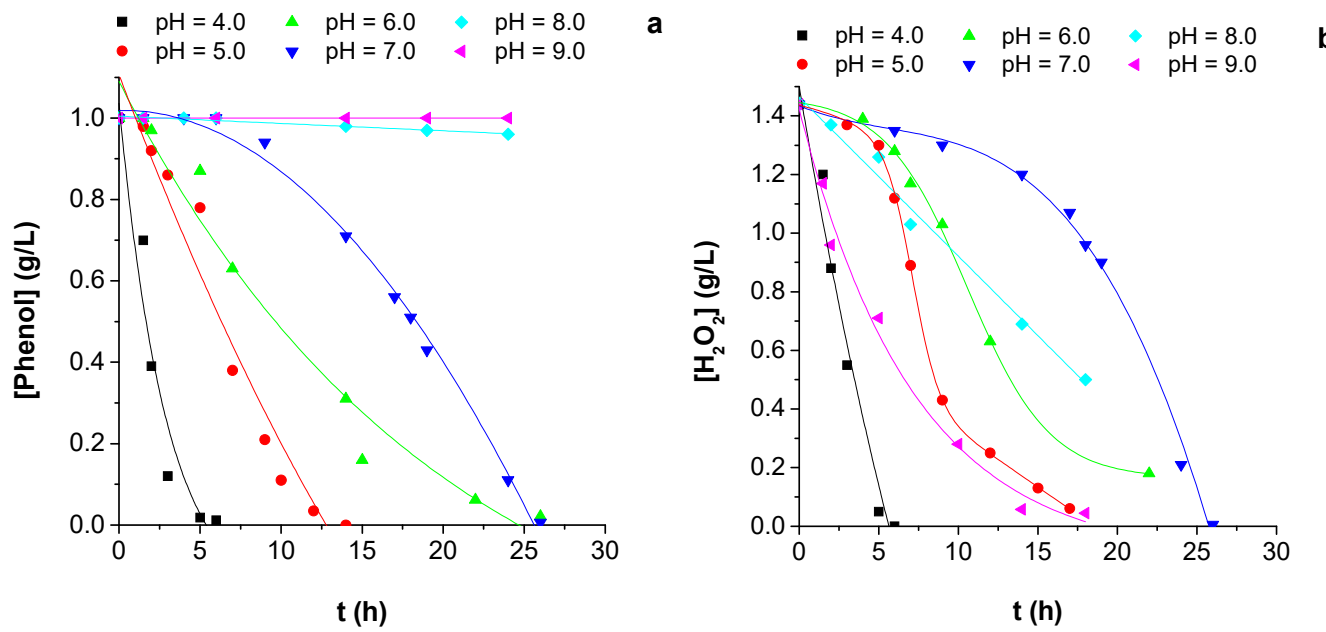

Figure 10. Effect of $\mathrm{pH}$ in phenol (a) and hydrogen peroxide (b) concentration during CWPO reaction with gold supported on diamond as catalyst at different $\mathrm{pH}$ values. Lines were added merely to better illustrate the data trends $\left([\text { phenol }]_{\text {initial }}=1.0 \mathrm{~g} / \mathrm{L},\left[\mathrm{H}_{2} \mathrm{O}_{2}\right]_{\text {initial }}=1.44 \mathrm{~g} / \mathrm{L}\right.$, [catalyst $]=320 \mathrm{mg} / \mathrm{L}$ and $\mathrm{T}=50^{\circ} \mathrm{C}$ ). Adapted from Martín et al. [73].

Studies of OII degradation by CWPO, without [66] and with radiation [110], using gold supported on alumina showed that the initial $\mathrm{pH}$ has an effect on the efficiency of the process. The authors observed optimum activity for initial $\mathrm{pH}=3$, which maximized the removal of OII ( $>97 \%)$ and TOC $(85.9 \%)$ (see Figure 11), as well as the generation of hydroxyl radicals. The formation of radicals was evaluated in runs carried out without OII dye and when hydroxyl radicals were formed, and thus became in contact with 1,5-diphenyl carbazide, 1,5-diphenyl carbazone was formed, which presented a brown color that was measured at $563 \mathrm{~nm}$. However, the oxidant consumption increased with $\mathrm{pH}$ (see Figure 11). As the support used in this study was alkaline, it increased the $\mathrm{pH}$ of the medium and, for the optimum initial $\mathrm{pH}$ found, the $\mathrm{pH}$ after $2 \mathrm{~h}$ of reaction was 4 , which is in agreement with the 
best $\mathrm{pH}$ value reported by Domínguez et al. [72] and Martín et al. [73]. In these studies, all oxidant was consumed and the gold did not leach into solution during the oxidation for the initial $\mathrm{pH}$ range tested.

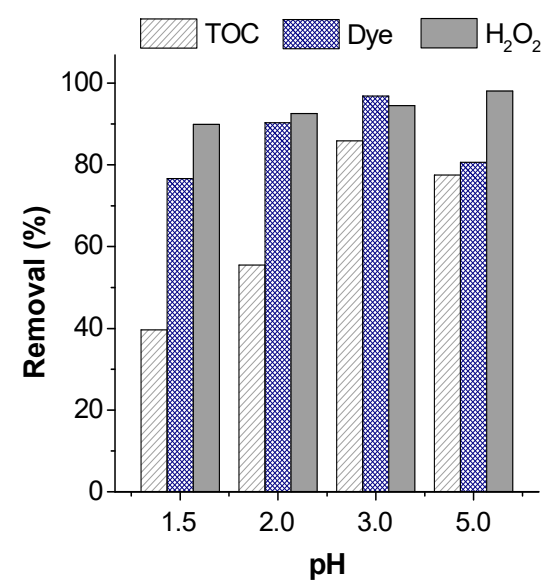

Figure 11. Removals of TOC and dye and hydrogen peroxide consumption, after $4 \mathrm{~h}$ of CWPO, with radiation, using $\mathrm{Au} / \mathrm{Al}_{2} \mathrm{O}_{3}$ as catalyst $\left([\mathrm{OII}]=0.1 \mathrm{mM},\left[\mathrm{H}_{2} \mathrm{O}_{2}\right]_{\text {initial }}=6 \mathrm{mM}\right.$, [catalyst $]=2.0 \mathrm{~g} / \mathrm{L}$, $\mathrm{T}=30{ }^{\circ} \mathrm{C}$ and $\mathrm{I}=500 \mathrm{~W} / \mathrm{m}^{2}$ ). Adapted from Rodrigues et al. [110].

In the work developed by Ferentz et al. [71], it was evaluated the degradation of phenol by CWPO using gold supported on titanium oxide. The TOC conversion increased with the $\mathrm{pH}$ of the phenol solution until 3.5 , reduced about $20 \%$ for $\mathrm{pH}$ in the range of $4-8$ and had a significant decrease for $\mathrm{pH}$ higher than 9. The authors explanation for the high $\mathrm{pH}$ effect on the efficiency of the process was associated with the adsorption of $\mathrm{H}_{2} \mathrm{O}_{2}$ on the titanium surface, which increases with the $\mathrm{pH}$ decrease. This is due to the dissociation of hydroxyl groups from the titanium surface, leading to the creation of Lewis acid sites $\left(\mathrm{Ti}^{4+}\right)$ that attach the hydrogen peroxide, leaving the surface of $\mathrm{Ti}\left(\mathrm{H}_{2} \mathrm{O}_{2}\right)^{4+}$ prone to $\mathrm{O}-\mathrm{O}$ bond cleavage forming the hydroxyl radical.

Navalon et al. [74] observed that the performance of CPWO, when using Au/HO-npD as a catalyst, was very affected by the $\mathrm{pH}$ of the phenol solution and the catalyst was abruptly inefficient at $\mathrm{pH}$ above 5 . This fact is explained by the change of the catalyst charge from positive $(\mathrm{pH}<5)$ to negative $(\mathrm{pH}>5)$. On the other hand, in this study, high gold leaching $(47 \%)$ was found, at $\mathrm{pH}$ less than 3 , that was much lower for $\mathrm{pH}$ higher than $3(0.7 \%$ at $\mathrm{pH} 4)$.

The effect of $\mathrm{pH}$ was evaluated in others studies that reached the best performances when using neutral or alkaline conditions (7.0-11.0) [70,75,108,111,115].

As mentioned above, the $\mathrm{pH}$ influences the efficiency of $\mathrm{CPWO}$, with the use of gold catalysts. In addition to the decomposition of $\mathrm{H}_{2} \mathrm{O}_{2}$ in water and oxygen (Equation (19)) in alkaline conditions, the $\mathrm{pH}$ affects the surface chemical properties of the support that influence the adsorption of the oxidant and, consequently, the generation of hydroxyl radicals, as reported in the study developed by Ferentz et al. [71]. Changes in the colloids charge can also occur, which also affect the adsorption of pollutants and oxidant as mentioned by Navalon et al. [74].

Concerning the industrial application perspective, the gold catalysts that allow the use of oxidative processes at neutral $\mathrm{pH}$ are more advantageous, because they reduce the costs associated with the acid consumption needed to decrease the $\mathrm{pH}$ to the acid range, and the base necessary to neutralize the effluent after the treatment, before it is discharged into the water bodies or subsequent treatment processes, as biological degradation.

\subsubsection{Temperature}

The temperature has a large influence on the efficiency of the CWPO process. The possibility to increase the operating temperature, as a way of improving the efficiency of the process, has been scarcely investigated, because the idea of thermal decomposition of $\mathrm{H}_{2} \mathrm{O}_{2}$ into $\mathrm{O}_{2}$ and $\mathrm{H}_{2} \mathrm{O}$ seems 
to be widely accepted as a serious drawback [11]. However, according to the Arrhenius law, higher temperatures (often up to ca. $50-70{ }^{\circ} \mathrm{C}$ ) can lead to a more efficient use of $\mathrm{H}_{2} \mathrm{O}_{2}$ upon enhanced generation of $\mathrm{HO}^{\bullet}$ radicals, at low metal concentrations. A decrease of the metal dose is important, since it improves the efficiency of $\mathrm{H}_{2} \mathrm{O}_{2}$ use, by minimizing competitive scavenging reactions [116]. Moreover, increasing the temperature accelerates oxidation of the organic compounds by the radicals.

Therefore, an increase in the temperature can be considered as a way to intensify the treatment process. Domínguez et al. [72] observed a positive effect of temperature, in the range of $50-80{ }^{\circ} \mathrm{C}$, in the removal of phenol by CWPO using gold supported on activated carbon. The same tendency was reported by Drašinac et al. [107], as the methyl orange dye removal increased from $\sim 30 \%$ at $25^{\circ} \mathrm{C}$ to $85 \%$ at $80^{\circ} \mathrm{C}$, after $250 \mathrm{~min}$ of reaction, when the process was catalyzed by gold supported on modified titanium nanotubes.

Martín et al. [73] found that the reaction rate of phenol degradation and hydrogen peroxide consumption, when using an $\mathrm{Au} / \mathrm{DNP}$ catalyst, increased with temperature in the range of $40-100{ }^{\circ} \mathrm{C}$, reducing the reaction time from $\sim 30 \mathrm{~h}$ to $\sim 2.5 \mathrm{~h}$, respectively, always reaching $100 \%$ compound removal and total consumption of oxidant. The same tendency was observed in a study that evaluated the methyl orange dye degradation, as its removal and TOC reduction increased with temperature in the range of 25 to $80^{\circ} \mathrm{C}$ (see Figure 12), reaching 85 and $83 \%$ for MO and TOC reduction, respectively, for the optimal temperature $\left(80^{\circ} \mathrm{C}\right)[107]$.

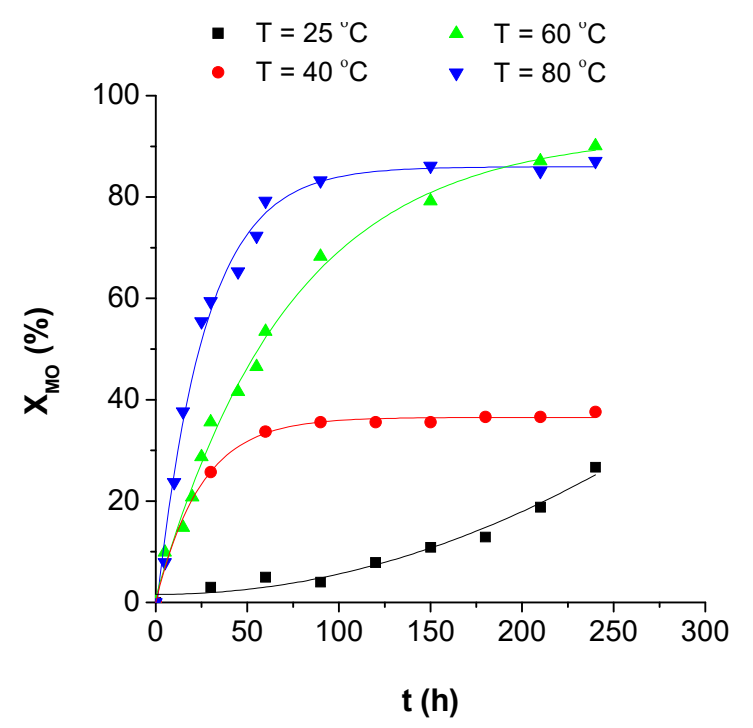

Figure 12. Methyl Orange (MO) decolorization during CWPO using gold supported on titanium nanotubes as catalyst, at different temperatures. Lines were added merely to better illustrate the data trends $\left([\mathrm{MO}]_{\text {initial }}=50 \mathrm{mg} / \mathrm{L},\left[\mathrm{H}_{2} \mathrm{O}_{2}\right]_{\text {initial }}=0.15 \mathrm{M}\right.$, [catalyst $]=2.0 \mathrm{~g} / \mathrm{L}$ and $\left.\mathrm{pH}_{\text {initial }}=3.0\right)$. Adapted from Drašinac et al. [107].

In contrast, the effect of decomposition of hydrogen peroxide in water and oxygen was observed in the works of Yang et al. [108] and Rodrigues et al. [66,110]. Yang et al. [108] observed a significant increase in bisphenol A degradation and consumption of the hydrogen peroxide during CWPO, using $\mathrm{Au} / \mathrm{SRAC}$ as catalyst, when the temperature increased from 30 to $40{ }^{\circ} \mathrm{C}$ (see Figure 13). Also when the temperature was raised to $50^{\circ} \mathrm{C}$, a little increase in the process efficiency was obtained. However, increasing the temperature to $60^{\circ} \mathrm{C}$, showed no improvement in the degradation of bisphenol A. 

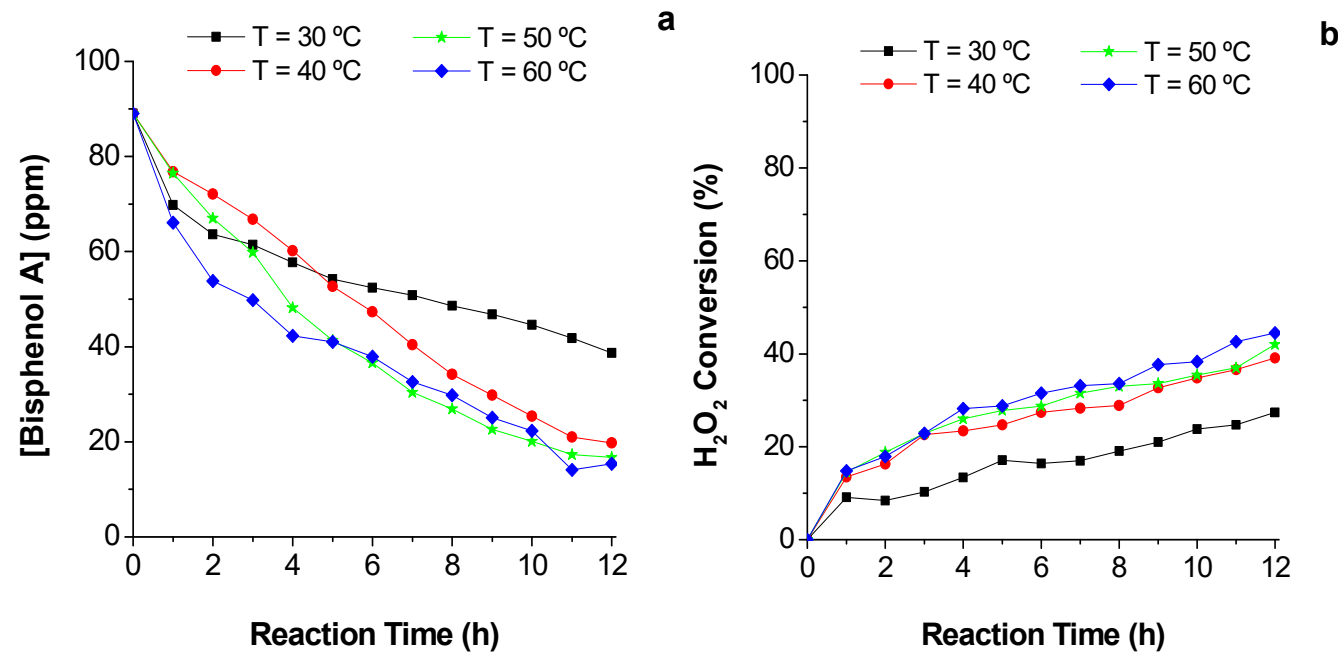

Figure 13. Effect of temperature in bisphenol A (BPA) concentration (a) and hydrogen peroxide conversion (b) during CWPO using Au/SRAC as catalyst $\left([\mathrm{BPA}]_{\text {initial }}=89 \mathrm{ppm},\left[\mathrm{H}_{2} \mathrm{O}_{2}\right]_{\text {initial }}=530 \mathrm{ppm}\right.$, [catalyst $]=125 \mathrm{ppm}$ and $\mathrm{pH}_{\text {initial }}=3.0$ ). Adapted from Yan et al. [108].

The application of wet peroxidation at high temperature can be beneficial in effluents that are generated at high temperature, as in the case of textile dye effluents [73], minimizing the energy costs for heating. However, for wastewater discharged from industrial processes at lower temperature, it may be more advantageous to apply a treatment process at moderate temperatures. In any case, a careful cost/benefit analysis should be made for each particular situation.

\subsubsection{Effect of radiation use}

In the literature, there are studies reporting the application of CWPO assisted with radiation. Table 4 shows an outline of these studies, reporting the operating conditions used and the efficiencies achieved. The use of radiation increases the rate of oxidation since there are additional mechanisms for the formation of free radicals, according to the following three processes: i) the catalytic decomposition $\mathrm{H}_{2} \mathrm{O}_{2}$ in the presence of radiation (Equation (20)) [42,117], ii) the decomposition of hydrogen peroxide by incidence of radiation (Equation (21)), and iii) photolysis of gold hydroxide (Equation (22)).

$$
\begin{gathered}
\mathrm{X}-\mathrm{Au}^{\mathrm{n}+}+\mathrm{H}_{2} \mathrm{O}_{2}+h v \rightarrow \mathrm{X}-\mathrm{Au}^{(\mathrm{n}+1)+}+\mathrm{HO}^{\bullet}+\mathrm{HO}^{-} \\
\mathrm{H}_{2} \mathrm{O}_{2}+h v \rightarrow 2 \mathrm{HO}^{\bullet} \\
\mathrm{X}-\mathrm{Au}(\mathrm{OH})^{\mathrm{n}+}+h v \rightarrow \mathrm{X}^{-} \mathrm{Au}^{\mathrm{n}+}+\mathrm{HO}^{\bullet}
\end{gathered}
$$

On the other hand, an improvement of the performance in radiation-assisted CWPO can also occur due to direct photolysis of the organic compounds to degrade.

Some authors report that an increased radiation intensity has a positive effect on the performance of the treatment process. Navalon et al. [74] showed that an increase of laser power from 0 to $70 \mathrm{~mJ} / \mathrm{pulse}$ improved the phenol degradation when Au/OH-npD catalyst was used. Rodrigues et al. [110] observed an increase of color and TOC removal, as well as of hydrogen consumption, with the radiation intensity of a TQ150 mercury lamp when $\mathrm{Au} / \mathrm{Al}_{2} \mathrm{O}_{3}$ was used as photo-catalyst. 
Table 4. Gold catalysts used in CWPO assisted with radiation for model compounds degradation or wastewater treatment, operational conditions, and performances reached.

\begin{tabular}{|c|c|c|c|c|}
\hline $\begin{array}{l}\text { Model } \\
\text { Compound/Effluent }\end{array}$ & Catalyst & Operation Conditions & $\begin{array}{c}\text { Efficiency of CWPO } \\
\text { assisted with Radiation }\end{array}$ & Ref. \\
\hline \multirow{3}{*}{ Phenol } & $\mathrm{Au} / \mathrm{FH}_{2}(0.1 \%)$ & $\begin{array}{c}\mathrm{pH}=4.0 ; \text { Room temperature; } \\
\text { [phenol] = } 100 \mathrm{mg} / \mathrm{L} ; \mathrm{t}=3.5 \mathrm{~h} ; \\
\text { Radiation: Sunlight }\end{array}$ & $\begin{array}{c}\text { Phenol removal }=100 \% \\
\mathrm{H}_{2} \mathrm{O}_{2} \text { consumption }=\sim 60 \%\end{array}$ & \multirow{3}{*}{ [75] } \\
\hline & $\mathrm{Au} / \mathrm{FN}_{2}(0.5 \%)$ & \multirow{2}{*}{$\begin{array}{c}\mathrm{pH}=4.0 ; \text { Room temperature; } \\
{\left[\mathrm{H}_{2} \mathrm{O}_{2}\right]=200 \mathrm{mg} / \mathrm{L} ;} \\
\text { [phenol] }=100 \mathrm{mg} / \mathrm{L} ; \mathrm{t}=8 \mathrm{~h} \\
\text { Radiation: Sunlight }\end{array}$} & $\begin{array}{c}\text { Phenol removal }=\sim 20 \% \\
\mathrm{H}_{2} \mathrm{O}_{2} \text { consumption }=\sim 20 \%\end{array}$ & \\
\hline & $\mathrm{Au} / \mathrm{F}(0.5 \%)$ & & $\begin{array}{c}\text { Phenol removal }=\sim 10 \% \\
\mathrm{H}_{2} \mathrm{O}_{2} \text { consumption }=\sim 15 \%\end{array}$ & \\
\hline $\begin{array}{l}\text { Acid Orange } 7 \text { dye } \\
\text { (AO7) }\end{array}$ & $\mathrm{Au} / \mathrm{CeO}_{2}$ (1.0 at.\%) & $\begin{array}{c}\mathrm{pH}=3.0 ; \mathrm{T}=30^{\circ} \mathrm{C} ; \\
{\left[\mathrm{H}_{2} \mathrm{O}_{2}\right]=20 \mathrm{mM} ;[\text { catalyst }]=0.5 \mathrm{~g} / \mathrm{L} ;} \\
{[\mathrm{AO}]=35 \mathrm{mg} / \mathrm{L} ; \mathrm{t}=6 \mathrm{~h} ; \text { Radiation: }} \\
\text { Visible light }\end{array}$ & Dye removal $=100 \%$ & [106] \\
\hline \multirow{6}{*}{ Orange II (OII) dye } & $\mathrm{Au} / \mathrm{Al}_{2} \mathrm{O}_{3}(0.7$ wt. $\%)$ & \multirow{5}{*}{$\begin{array}{c}\mathrm{pH}=3.0 ; \mathrm{T}=30^{\circ} \mathrm{C} ;\left[\mathrm{H}_{2} \mathrm{O}_{2}\right]=6 \mathrm{mM} \\
{[\text { catalyst }]=2.0 \mathrm{~g} / \mathrm{L} ;[\mathrm{OII}]=0.1 \mathrm{mM}} \\
\mathrm{t}=2 \mathrm{~h} ; \text { Radiation: UV/visible light } \\
\left(500 \mathrm{~W} / \mathrm{m}^{2}\right)\end{array}$} & $\begin{array}{c}\text { Dye removal }=96.8 \% ; \text { TOC } \\
\text { removal }=80.5 \%\end{array}$ & \multirow{7}{*}[110]{} \\
\hline & $\mathrm{Au} / \mathrm{Fe}_{2} \mathrm{O}_{3}(0.8$ wt. $\%)$ & & $\begin{array}{c}\text { Dye removal }=97.8 \% ; \text { TOC } \\
\text { removal }=68.2 \%\end{array}$ & \\
\hline & $\begin{array}{l}\mathrm{Au} / \mathrm{Fe}_{2} \mathrm{O}_{3}(4.0 \mathrm{wt} . \%) \\
\text { from WGC }\end{array}$ & & $\begin{array}{c}\text { Dye removal }=96.9 \% ; \mathrm{TOC} \\
\text { removal }=58.4 \%\end{array}$ & \\
\hline & $\mathrm{Au} / \mathrm{TiO}_{2}(1.6$ wt.\%) & & $\begin{array}{c}\text { Dye removal }=98.5 \% ; \text { TOC } \\
\text { removal }=73.5 \%\end{array}$ & \\
\hline & $\mathrm{Au} / \mathrm{ZnO}(1.2$ wt.\%) & & $\begin{array}{c}\text { Dye removal }=99.8 \% ; \text { TOC } \\
\text { removal }=73.4 \%\end{array}$ & \\
\hline & $\mathrm{Au} / \mathrm{Al}_{2} \mathrm{O}_{3}(0.7$ wt. $\%)$ & $\begin{array}{c}\mathrm{pH}=3.0 ; \mathrm{T}=50^{\circ} \mathrm{C} ;\left[\mathrm{H}_{2} \mathrm{O}_{2}\right]=3 \mathrm{mM} ; \\
{[\text { catalyst }]=2.0 \mathrm{~g} / \mathrm{L} ;[\mathrm{OII}]=0.1 \mathrm{mM} ;} \\
\mathrm{t}=2 \mathrm{~h} ; \text { Radiation: UV/visible light } \\
\left(500 \mathrm{~W} / \mathrm{m}^{2}\right)\end{array}$ & $\begin{array}{c}\text { Dye removal }=99.3 \% ; \text { TOC } \\
\text { removal }=90.9 \% ; \mathrm{H}_{2} \mathrm{O}_{2} \\
\text { consumption }=98.6 \% ; \text { Gold } \\
\text { leaching }<0.5 \mathrm{mg} / \mathrm{L}\end{array}$ & \\
\hline $\begin{array}{l}\text { Acrylic dyeing } \\
\text { wastewater }\end{array}$ & $\mathrm{Au} / \mathrm{Al}_{2} \mathrm{O}_{3}(0.7$ wt. $\%)$ & $\begin{array}{c}\mathrm{pH}=3.0 ; \mathrm{T}=50^{\circ} \mathrm{C} ; \\
{\left[\mathrm{H}_{2} \mathrm{O}_{2}\right]=104 \mathrm{mM} ;} \\
{[\text { catalyst }]=2.0 \mathrm{~g} / \mathrm{L} ; \mathrm{t}=2 \mathrm{~h} ;} \\
\text { Radiation: } \mathrm{UV} / \text { visible light } \\
\left(500 \mathrm{~W} / \mathrm{m}^{2}\right)\end{array}$ & $\begin{array}{l}\text { Color removal }=100 \% \text {; TOC } \\
\text { removal }=72.4 \% ; \mathrm{COD} \\
\text { removal }=70.0 \% ; \\
\mathrm{BOD}_{5}: \mathrm{COD}=0.5 ; \text { Specific } \\
\text { Oxygen Uptake Rate }=17.9 \mathrm{mgO}_{2} /\left(\mathrm{g}_{\mathrm{vSs}} \mathrm{h}\right) ; \text { Inhibition of } \\
\text { Vibrio Fischeri }=0.0 \%\end{array}$ & \\
\hline Phenol & $\mathrm{Au} / \mathrm{HO}-\mathrm{npD}(1.0 \mathrm{wt} \%)$ & $\begin{array}{c}\mathrm{pH}=4.0 ; \mathrm{T}=30^{\circ} \mathrm{C} \\
{\left[\mathrm{H}_{2} \mathrm{O}_{2}\right]=2.5 \mathrm{~g} / \mathrm{L} ;} \\
{[\text { catalyst }]=400 \mathrm{mg} / \mathrm{L}} \\
\text { [phenol] }=100 \mathrm{mg} / \mathrm{L} ; \mathrm{t}=2 \mathrm{~h} \\
\text { Radiation: Sunlight }\end{array}$ & $\begin{array}{c}\text { Phenol removal }=100 \% \\
\mathrm{H}_{2} \mathrm{O}_{2} \text { consumption }=100 \% ; \\
\text { COD removal }=69.7 \% \\
\mathrm{BOD}_{5}: \mathrm{COD}=0.4\end{array}$ & [111] \\
\hline \multirow{3}{*}{ Phenol } & $\mathrm{Au} / \mathrm{HO}-\mathrm{npD}(1.0 \mathrm{wt} \%)$ & $\begin{array}{c}\mathrm{pH}=4.0 ;\left[\mathrm{H}_{2} \mathrm{O}_{2}\right]=200 \mathrm{mg} / \mathrm{L} \\
\text { [catalyst] }=160 \mathrm{mg} / \mathrm{L} ; \\
\text { [phenol] = } 100 \mathrm{mg} / \mathrm{L} ; \mathrm{t}=2 \mathrm{~h} \\
\text { Radiation: Laser Flash }(70 \mathrm{~mJ} / \mathrm{pulse})\end{array}$ & $\begin{array}{c}\text { Phenol removal }=100 \% \\
\mathrm{H}_{2} \mathrm{O}_{2} \text { consumption }=\sim 90 \%\end{array}$ & \multirow{3}{*}{ [115] } \\
\hline & $\mathrm{Au} / \mathrm{CeO}_{2}(1.0 \mathrm{wt} \%)$ & \multirow{2}{*}{$\begin{array}{c}\mathrm{pH}=4.0 ;\left[\mathrm{H}_{2} \mathrm{O}_{2}\right]=200 \mathrm{mg} / \mathrm{L} \\
\text { [catalyst] }=160 \mathrm{mg} / \mathrm{L} ; \\
\text { [phenol] }=100 \mathrm{mg} / \mathrm{L} ; \mathrm{t}=3 \mathrm{~h} \\
\text { Radiation: Laser Flash }(70 \mathrm{~mJ} / \text { pulse })\end{array}$} & $\begin{array}{c}\text { Phenol removal }=\sim 15 \% \\
\mathrm{H}_{2} \mathrm{O}_{2} \text { consumption }=\sim 100 \%\end{array}$ & \\
\hline & $\mathrm{Au} / \mathrm{TiO}_{2}(1.0 \mathrm{wt} \%)$ & & $\begin{array}{c}\text { Phenol removal }=\sim 10 \% \\
\mathrm{H}_{2} \mathrm{O}_{2} \text { consumption }=\sim 80 \%\end{array}$ & \\
\hline
\end{tabular}

\subsection{Catalyst Stability}

The deactivation of catalysts in CWPO is mostly associated with the loss of metal by leaching from the solid support to the effluent during the treatment process, but also with possible gold nanoparticle sintering and/or pore blockage. For application of catalytic wet peroxidation in the treatment of real effluents, a crucial aspect to be taken into account is the reutilization of the catalysts, without reduction of their efficiency and stability in consecutive cycles of use, making it imperative to evaluate how stable and durable they are.

Ferentz et al. [71] evaluated the long-term stability of $\mathrm{Au} / \mathrm{TiO}_{2}$, with 2.8 and $3.2 \mathrm{Au}$ wt.\%, in a fixed bed reactor. The first catalyst was stable during $50 \mathrm{~h}$, achieving constant removals of TOC and phenol $>90$ and $>99 \%$, respectively. In the period of 50 to $75 \mathrm{~h}$, the efficiency of CWPO dropped to $\sim 65 \%$ of 
TOC removal and remained constant for higher reaction times, corresponding to the performance reached with pristine $\mathrm{TiO}_{2}$. The authors associated the deactivation of the catalyst to the gold particles growth (as the size increased from 3-4 nm in the fresh catalyst to 20-30 nm after CWPO). For the second catalyst $\left(3.2 \mathrm{wt} . \% \mathrm{Au} / \mathrm{TiO}_{2}\right)$, the efficiency of the process, in terms of TOC removal, decreased from $\sim 95 \%$ to $\sim 80 \%$ during the first $50 \mathrm{~h}$ of reaction and remained practically constant for higher reaction times. This loss of catalytic activity was attributed to: i) an increase of the gold size from 7-8 nm to 13-15 $\mathrm{nm}$ for fresh and used catalysts after $300 \mathrm{~h}$, respectively, and ii) adsorption of dicarboxylates in gold, with the equilibrium established at $50 \mathrm{~h}$.

In the work developed by Domínguez et al. [72], the activated carbon supported gold deactivated in the first cycle of CWPO of phenol. The removal of the model compound observed by the authors in next three cycles was attributed to the activity of activated carbon alone (see Figure 14). Since the authors did not observe any gold leaching for the solution, the catalyst deactivation was attributed to the presence of dicarboxylic acids (by-products formed in the oxidation of phenol), which adsorb on gold nanoparticles. In order to recover the catalytic activity, the catalyst was regenerated after the first cycle by: i) alkaline washing to $\mathrm{pH} 14$ with $\mathrm{Na}_{2} \mathrm{CO}_{3}$, in order to dissolve the absorbed species, and subsequent washing with distilled water until neutralization, and ii) oxidative thermal treatment at $200{ }^{\circ} \mathrm{C}$, during $14 \mathrm{~h}$, in air atmosphere, which allowed to burn-off the carboxylic acids adsorbed on the gold nanoparticles. The first regeneration process led to an activity recovery of about $60 \%$ and the catalyst loss was $2 \mathrm{wt} . \%$ of gold by leaching. For the second process, a more significant loss of gold (10 wt.\%) was observed, however, the catalyst activity was fully restored (see Figure 14).

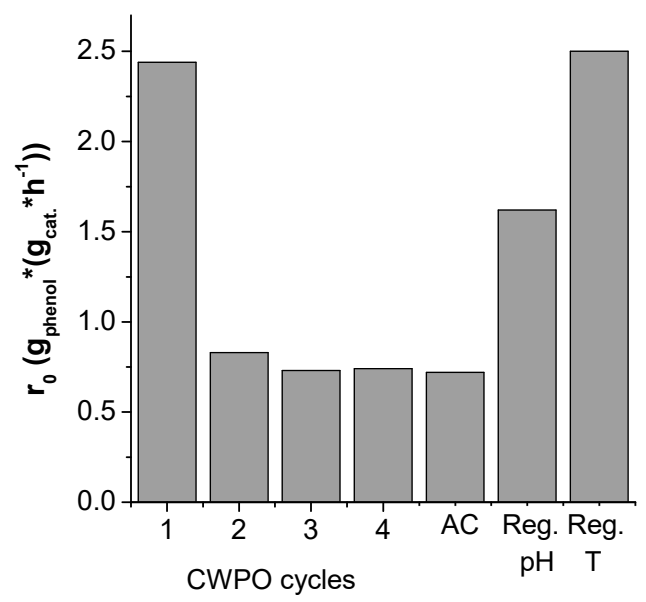

Figure 14. Initial rate of phenol degradation during four consecutives cycles of CWPO using gold supported on activated carbon and after regeneration $\left([\mathrm{phenol}]_{\text {initial }}=5 \mathrm{~g} / \mathrm{L},\left[\mathrm{H}_{2} \mathrm{O}_{2}\right]=25 \mathrm{~g} / \mathrm{L}, \mathrm{pH}=3.5\right.$ and $\left.\mathrm{T}=80^{\circ} \mathrm{C}\right)$. Adapted from Domínguez et al. [72].

In contrast to Ferentz et al. [71] and Domínguez et al. [72] that reported a loss of the catalytic activity of gold catalysts during CWPO, several studies in the literature refer to the stability of gold on different solid supports $[66,67,70,73,108,110]$ when used in subsequent reutilization cycles. In the investigations performed by Rodrigues et al. $[66,67,110]$, the gold supported on alumina, zinc oxide, titanium oxide, and iron oxide was stable during $3-5$ consecutive cycles in acid medium $(\mathrm{pH}=3.0)$, with OII and TOC removals and $\mathrm{H}_{2} \mathrm{O}_{2}$ consumption remaining unchanged during the cycles. The authors observed no catalyst loss of gold by leaching during the reactions.

Gold supported on activated carbon also did not deactivate in acidic $\mathrm{pH}$ (3.0) for degradation of bisphenol A by CWPO, with the removal of BPA and the consumption of oxidant being more or less constant, in $\sim 80$ and $\sim 40 \%$, respectively, during four consecutive cycles. This demonstrates that the catalyst can be reused several times [108]. The same tendency was observed by Han et al. [70], who evaluated the stability of gold supported on hydroxyapatite, showing that the conversion of phenol was constant after five cycles, either at $\mathrm{pH} 2.0(>90 \%)$ or $5.0(\sim 80 \%)$ (see Figure 15$)$. Similar results were 
obtained by Sempere et al. [75] that reused diamond supported gold (submitted to a thermal treatment at $420^{\circ} \mathrm{C}$ and subsequent annealing treatment with hydrogen) three times in sunlight assisted CWPO in the oxidation of phenol. This catalyst did not lose the catalytic activity and the leaching of gold was negligible $(<1 \%$ of the initial gold in the first cycle of utilization) or was not observed (in the second and third cycles).

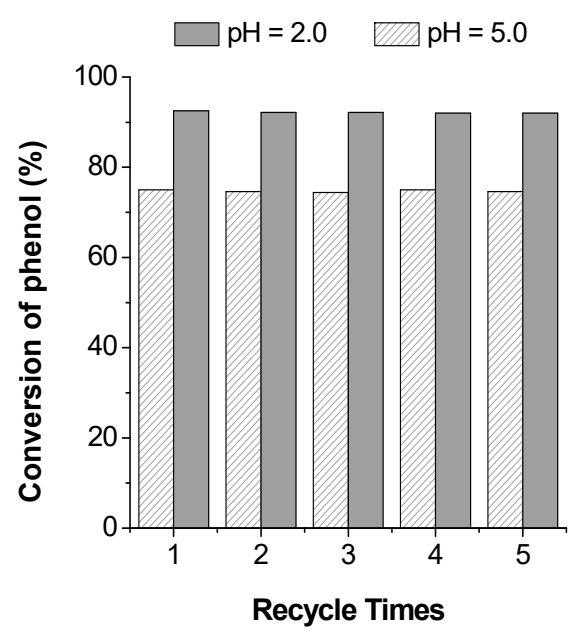

Figure 15. Conversion of phenol by CWPO using gold supported on hydroxyapatite as catalyst in consecutive five cycles of reutilization at $\mathrm{pH}=2.0$ and 5.0 ([phenol] $=100 \mathrm{mg} / \mathrm{L}, \mathrm{T}=70{ }^{\circ} \mathrm{C}$, [catalyst] $=0.1 \mathrm{~g} / \mathrm{L}$ and $\mathrm{V}_{\mathrm{H} 2 \mathrm{O} 2 \text { with } 30 \mathrm{wt} . \%}=1 \mathrm{~mL}$ ). Adapted from Han et al. [70].

Martín et al. [73] evaluated the reuse of a diamond supported gold (Au/DNP) catalyst in phenol oxidation by CWPO during four cycles. The authors exhaustively washed the material with water at $\mathrm{pH}=10$ and, finally, with distilled water, in order to eliminate the deactivation of the catalyst by adsorption of carboxylic acids (intermediate products generated by phenol oxidation) on gold, as also pointed out by Domínguez et al. [72] as the main reason for deactivation. The Au/DNP, after a simple treatment by washing, can be reused during four times, reaching, in all cycles, not only total conversion of phenol and consumption of $\mathrm{H}_{2} \mathrm{O}_{2}$ in the end of reaction, but the same temporal profiles [73] (see Figure 16). However, the washing of the catalyst led to a loss of gold to the solution, but the leaching decreased with an increase of the cycles (from 3 to $<0.1 \mathrm{wt} . \%$ after 1 st use and 4 th use, respectively), so that the performance of the catalyst was not affected by the small leaching and no deactivation was found [73].
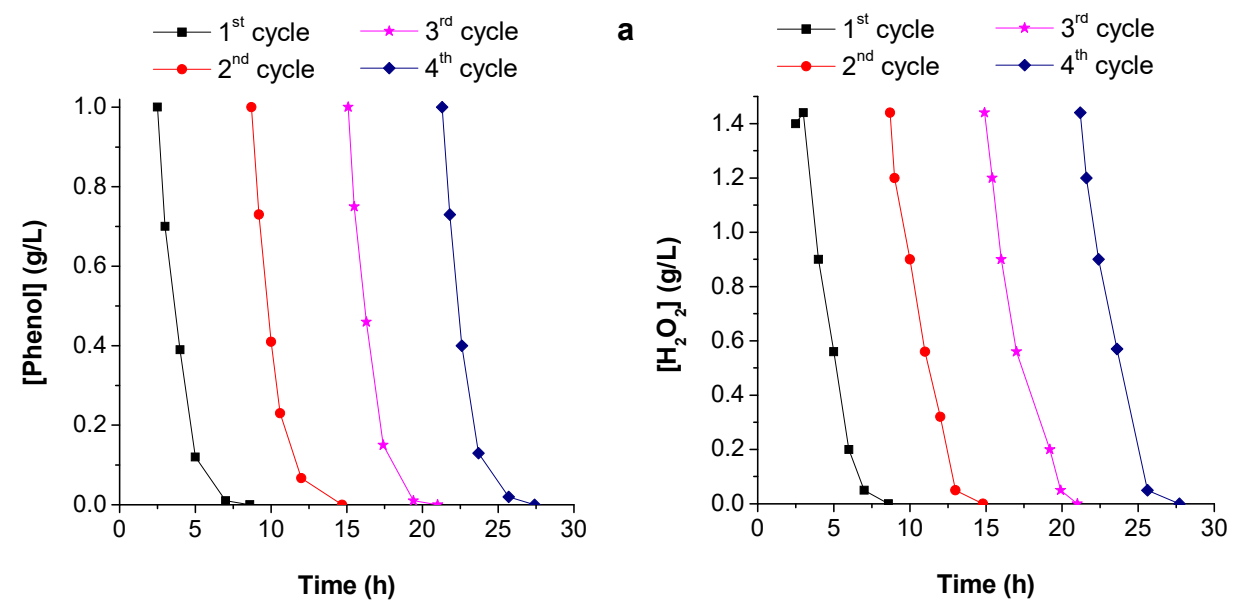

Figure 16. Evolution of phenol (a) and hydrogen peroxide (b) concentration during consecutive reuse cycles $\left([\right.$ phenol $]=1 \mathrm{~g} / \mathrm{L}, \mathrm{T}=50{ }^{\circ} \mathrm{C}, \mathrm{pH}=4.0,[\mathrm{Au} / \mathrm{DNP}]=320 \mathrm{mg} / \mathrm{L}$ and $\left.\left[\mathrm{H}_{2} \mathrm{O}_{2}\right]=1.44 \mathrm{~g} / \mathrm{L}\right)$. Adapted from Martín et al. [73]. 
Navalon et al. [74] reused $\mathrm{Au} / \mathrm{HO}-\mathrm{npD}$ catalysts during three consecutive cycles, washing with water at $\mathrm{pH} 10$ after each cycle. The authors did not observe any significant change in phenol and $\mathrm{H}_{2} \mathrm{O}_{2}$ disappearance profiles. Additionally, a run was carried out with a large excess of pollutant $(40 \mathrm{~g} / \mathrm{L})$ and $0.5 \mathrm{mg} / \mathrm{L}$ of catalyst, in order to have an equivalent of 400 consecutive reuse cycles and use 5.5 equivalent of oxidant with respect to phenol. This run allowed to conclude that $\mathrm{Au} / \mathrm{HO}-\mathrm{nDP}$ had the ability to remove $36 \%$ of the pollutant before being deactivated, however, an alkaline washing before the second and third cycles allowed the catalyst to recover the catalytic activity.

\section{Conclusions}

This review showed that gold catalysts can be efficiently used in CWPO processes and that their catalytic activity depends on several operational variables of the process (such as $\mathrm{pH}$, temperature, oxidant and catalyst concentrations, and gold content), as well as on the properties of the catalysts. We believe that such gathered information will provide useful insights that might lead to a more rapid and effective optimization of catalytic wet peroxidation processes using these materials.

Despite the recent progresses in this area, it is still crucial that work continues to be done to better apply these catalysts in the treatment of real effluents by CWPO and to deepen the knowledge coming from the laboratory studies for the scale-up of the process. The main limiting step in the application of this technology might be the costs of the treatment, since gold has a high cost (compared to other more common materials); however, gold also shows advantages, namely, high stability, high efficiency, and absence of leaching into the solution, which might justify the investment.

Acknowledgments: This work was financially supported by projects UID/EQU/00511/2019 - Laboratory for Process Engineering, Environment, Biotechnology and Energy - LEPABE - and by Associate Laboratory LSRE-LCM UID/EQU/50020/2019 - funded by national (Portuguese) funds through FCT/MCTES (PIDDAC). SACC is thankful to FCT for Investigador FCT program (IF/01381/2013/CP1160/CT0007), with financing from the European Social Fund and the Human Potential Operational Program (POCH).

Conflicts of Interest: The authors declare no conflict of interest.

\section{Abbreviations}

$\begin{array}{ll}\mathrm{AO} 7 & \text { Acid Orange dye } \\ \mathrm{AOPs} & \text { Advanced Oxidation Processes } \\ \mathrm{Au} / \mathrm{AC} & \text { Gold on activated carbon } \\ \mathrm{Au} / \mathrm{C} & \text { Gold on carbon } \\ \mathrm{Au} / \mathrm{CNF} & \text { Gold on carbon nanofibers } \\ \mathrm{Au} / \mathrm{CNT} & \text { Gold on carbon nanotubes } \\ \mathrm{Au} / \mathrm{X} 40 \mathrm{~s} & \text { Gold on coconut shell carbon } \\ \mathrm{Au} / \mathrm{DNP} & \text { Gold on diamond nanoparticles } \\ \mathrm{Au} / \mathrm{F} & \text { Gold on diamond after thermal treatment at } 420^{\circ} \mathrm{C} \text { in air atmosphere } \\ \mathrm{Au} / \mathrm{FH} & \text { Gold on diamond after thermal treatment at } 420^{\circ} \mathrm{C} \text { in air atmosphere and } 500{ }^{\circ} \mathrm{C} \text { in } \\ & \text { hydrogen atmosphere } \\ \mathrm{Au} / \mathrm{FN} 2 & \text { Gold on diamond after thermal treatment at } 420^{\circ} \mathrm{C} \text { in air atmosphere and at } 500{ }^{\circ} \mathrm{C} \text { in } \\ & \text { nitrogen atmosphere } \\ \mathrm{Au} / \mathrm{Hap} & \text { Gold on hydroxyapatite } \\ \mathrm{Au} / \mathrm{npD} & \text { Gold on nano power diamond } \\ \mathrm{Au} / \mathrm{HO}-\mathrm{npD} & \text { Gold on nano power diamond previously treated with Fenton reagent } \\ \mathrm{Au} / \mathrm{FDU}-15 & \text { Gold on ordered mesoporous carbon } \\ \mathrm{Au} / \mathrm{PSAC} & \text { Gold on pitch-based spherical activated carbon } \\ \mathrm{Au} / \mathrm{SRAC} & \text { Gold on styrene-based activated carbon } \\ \mathrm{Au} / \mathrm{TN} & \text { Gold on titanium nanotubes functionalization with hydrogen peroxide } \\ \mathrm{Au} / \mathrm{TiO} 2-\mathrm{AD} & \text { Gold on titanium oxide prepared by adsorption method } \\ \mathrm{BOD} 5 & \text { Biological oxygen demand after } 5 \text { days } \\ \mathrm{BPA} & \text { Bisphenol A } \\ \mathrm{CWPO} & \text { Catalytic Wet Peroxidation }\end{array}$




$\begin{array}{ll}\text { COD } & \text { Chemical oxygen demand } \\ \text { DM } & \text { Gold metal dispersion } \\ \text { DPPH } & \text { 1,1-diphenyl-2-picrylhydzazyl } \\ \text { EU-WFD } & \text { European Union Water Framework Directive } \\ \text { HR-TEM } & \text { High-resolution transmission electron microscopy } \\ h v & \text { Ultraviolet radiation } \\ \text { M } & \text { Transmission of metallic cations } \\ \text { MB } & \text { Methyl Blue dye } \\ \text { MO } & \text { Methyl Orange dye } \\ \text { NHE } & \text { Normal hydrogen electrode } \\ \text { OII } & \text { Orange II dye } \\ \text { RH } & \text { Organic matter } \\ \text { TOC } & \text { Total organic carbon } \\ \text { TOF } & \text { Turn off frequency } \\ \text { WGC } & \text { World Gold Council } \\ \text { X } & \text { Support }\end{array}$

\section{References}

1. Zeng, G.-M.; Li, X.; Huang, J.-H.; Zhang, C.; Zhou, C.-F.; Niu, J.; Shi, L.-J.; He, S.-B.; Li, F. Micellar-enhanced ultrafiltration of cadmium and methylene blue in synthetic wastewater using sds. J. Hazard. Mater. 2011, 185, 1304-1310. [CrossRef]

2. Cundy, A.B.; Hopkinson, L.; Whitby, R.L.D. Use of iron-based technologies in contaminated land and groundwater remediation: A review. Sci. Total Environ. 2008, 400, 42-51. [CrossRef] [PubMed]

3. Chong, M.N.; Jin, B.; Chow, C.W.K.; Saint, C. Recent developments in photocatalytic water treatment technology: A review. Water Res. 2010, 44, 2997-3027. [CrossRef] [PubMed]

4. O'Connor, G.A. Organic compounds in sludge-amended soils and their potential for uptake by crop plants. Sci. Total Environ. 1996, 185, 71-81. [CrossRef]

5. Li, X.; Zeng, G.-M.; Huang, J.-H.; Zhang, D.-M.; Shi, L.-J.; He, S.-B.; Ruan, M. Simultaneous removal of cadmium ions and phenol with meuf using sds and mixed surfactants. Desalination 2011, 276, 136-141. [CrossRef]

6. Fatta-Kassinos, D.; Kalavrouziotis, I.K.; Koukoulakis, P.H.; Vasquez, M.I. The risks associated with wastewater reuse and xenobiotics in the agroecological environment. Sci. Total Environ. 2011, 409, 3555-3563. [CrossRef] [PubMed]

7. Xu, P.; Zeng, G.M.; Huang, D.L.; Feng, C.L.; Hu, S.; Zhao, M.H.; Lai, C.; Wei, Z.; Huang, C.; Xie, G.X.; et al. Use of iron oxide nanomaterials in wastewater treatment: A review. Sci. Total Environ. 2012, 424, 1-10. [CrossRef]

8. European Parliament \& Council. Water Framework Directive 2000/60/ce; European Parliament \& Counci: Brussels, Belgium, 2000; pp. 1-73.

9. Oturan, M.A.; Aaron, J.-J. Advanced oxidation processes in water/wastewater treatment: Principles and applications. A review. Crit. Rev. Environ. Sci. Technol. 2014, 44, 2577-2641. [CrossRef]

10. Bokare, A.D.; Choi, W. Review of iron-free Fenton-like systems for activating $\mathrm{H}_{2} \mathrm{O}_{2}$ in advanced oxidation processes. J. Hazard. Mater. 2014, 275, 121-135. [CrossRef]

11. Gogate, P.R.; Pandit, A.B. A review of imperative technologies for wastewater treatment I: Oxidation technologies at ambient conditions. Adv. Environ. Res. 2004, 8, 501-551. [CrossRef]

12. Seow, T.W.; Lim, C.K.; Norb, M.H.M.; Mubarak, M.F.M.; Lam, C.Y.L.; Yahya, A.; Ibrahim, Z. Review on wastewater treatment technologies. Int. J. Appl. Environ. Sci. 2016, 11, 111-126.

13. Ramalho, R.S. Introduction to Wastewater Treatment Processes; Academic Press: New York, NY, USA, 1977.

14. Pant, D.; Adholeya, A. Biological approaches for treatment of distillery wastewater: A review. Bioresour. Technol. 2007, 98, 2321-2334. [CrossRef]

15. Demirel, B.; Yenigun, O.; Onay, T.T. Anaerobic treatment of dairy wastewaters: A review. Process Biochem. 2005, 40, 2583-2595. [CrossRef]

16. Wolfe, S.; Ingold, C.F. Oxidation of organic compounds by zinc permanganate. J. Am. Chem. Soc. 1983, 105, 7755-7757. [CrossRef] 
17. Xu, X.-R.; Li, H.-B.; Wang, W.-H.; Gu, J.-D. Decolorization of dyes and textile wastewater by potassium permanganate. Chemosphere 2005, 59, 893-898. [CrossRef]

18. Calvosa, L.; Monteverdi, A.; Rindone, B.; Riva, G. Ozone oxidation of compounds resistant to biological degradation. Water Res. 1991, 25, 985-993. [CrossRef]

19. Stasinakis, A.S. Use of selected advanced oxidation processes (aops) for wastewater treatment-A mini review. Glob. NEST J. 2008, 10, 376-385.

20. Azbar, N.; Yonar, T.; Kestioglu, K. Comparison of various advanced oxidation processes and chemical treatment methods for COD and color removal from a polyester and acetate fiber dyeing effluent. Chemosphere 2004, 55, 35-43. [CrossRef]

21. Lamarche, P.; Droste, R.L. Air-stripping mass transfer correlations for volatile organics. J. Am. Water Works Assoc. 1989, 81, 78-89. [CrossRef]

22. Busca, G.; Berardinelli, S.; Resini, C.; Arrighi, L. Technologies for the removal of phenol from fluid streams: A short review of recent developments. J. Hazard. Mater. 2008, 160, 265-288. [CrossRef] [PubMed]

23. Andreozzi, R.; Caprio, V.; Insola, A.; Marotta, R. Advanced oxidation processes (AOP) for water purification and recovery. Catal. Today 1999, 53, 51-59. [CrossRef]

24. Poyatos, J.M.; Muñio, M.M.; Almecija, M.C.; Torres, J.C.; Hontoria, E.; Osorio, F. Advanced oxidation processes for wastewater treatment: State of the art. Water Air Soil Pollut. 2010, 205, 187-204. [CrossRef]

25. Skoumal, M.; Cabot, P.-L.; Centellas, F.; Arias, C.; Rodríguez, R.M.; Garrido, J.A.; Brillas, E. Mineralization of paracetamol by ozonation catalyzed with $\mathrm{Fe}^{2+}, \mathrm{Cu}^{2+}$ and UVA light. Appl. Catal. B Environ. 2006, 66, 228-240. [CrossRef]

26. Rosenfeldt, E.J.; Chen, P.J.; Kullman, S.; Linden, K.G. Destruction of estrogenic activity in water using UV advanced oxidation. Sci. Total Environ. 2007, 377, 105-113. [CrossRef]

27. Haber, F.; Weiss, J. The catalytic decomposition of hydrogen peroxide by iron salts. Proc. R. Soc. Lond. Ser. A Math. Phys. Sci. 1934, 147, 332-351.

28. Mahamuni, N.N.; Adewuyi, Y.G. Advanced oxidation processes (aops) involving ultrasound for waste water treatment: A review with emphasis on cost estimation. Ultrason. Sonochem. 2010, 17, 990-1003. [CrossRef]

29. Herney-Ramirez, J.; Vicente, M.A.; Madeira, L.M. Heterogeneous photo-Fenton oxidation with pillared clay-based catalysts for wastewater treatment: A review. Appl. Catal. B Environ. 2010, 98, 10-26. [CrossRef]

30. Esteves, B.M.; Rodrigues, C.S.D.; Madeira, L.M. Wastewater treatment by heterogeneous Fenton-like processes in continuous reactors. In Applications of Advanced Oxidation Processes (AOPs) in Drinking Water Treatment; Gil, A., Galeano, L.A., Vicente, M.Á., Eds.; Springer International Publishing: Cham, Switzerland, 2019; pp. 211-255.

31. Pawłat, J.; Stryczewska Henryka, D.; Ebihara, K. Sterilization techniques for soil remediation and agriculture based on ozone and AOP. J. Adv. Oxid. Technol. 2010, 13, 138-145. [CrossRef]

32. Flotron, V.; Delteil, C.; Padellec, Y.; Camel, V. Removal of sorbed polycyclic aromatic hydrocarbons from soil, sludge and sediment samples using the Fenton's reagent process. Chemosphere 2005, 59, 1427-1437. [CrossRef]

33. Tokumura, M.; Nakajima, R.; Znad, H.T.; Kawase, Y. Chemical absorption process for degradation of voc gas using heterogeneous gas-liquid photocatalytic oxidation: Toluene degradation by photo-Fenton reaction. Chemosphere 2008, 73, 768-775. [CrossRef]

34. Liu, G.; Ji, J.; Huang, H.; Xie, R.; Feng, Q.; Shu, Y.; Zhan, Y.; Fang, R.; He, M.; Liu, S.; et al. UV/ $\mathrm{H}_{2} \mathrm{O}_{2}$ : An efficient aqueous advanced oxidation process for VOCs removal. Chem. Eng. J. 2017, 324, 44-50. [CrossRef]

35. Domeño, C.; Rodríguez-Lafuente, Á.; Martos, J.; Bilbao, R.; Nerín, C. VOC removal and deodorization of effluent gases from an industrial plant by photo-oxidation, chemical oxidation, and ozonization. Environ. Sci. Technol. 2010, 44, 2585-2591. [CrossRef]

36. Tokumura, M.; Shibusawa, M.; Kawase, Y. Dynamic simulation of degradation of toluene in waste gas by the photo-Fenton reaction in a bubble column. Chem. Eng. Sci. 2013, 100, 212-224. [CrossRef]

37. Toor, R.; Mohseni, M. UV- $\mathrm{H}_{2} \mathrm{O}_{2}$ based AOP and its integration with biological activated carbon treatment for dbp reduction in drinking water. Chemosphere 2007, 66, 2087-2095. [CrossRef] [PubMed]

38. Shannon, M.A.; Bohn, P.W.; Elimelech, M.; Georgiadis, J.G.; Mariñas, B.J.; Mayes, A.M. Science and technology for water purification in the coming decades. Nature 2008, 452, 301-310. [CrossRef] [PubMed] 
39. Comninellis, C.; Kapalka, A.; Malato, S.; Parsons, S.A.; Mantzavinos, I.P.D. Advanced oxidation processes for water treatment: Advances and trends for r\&d. J. Chem. Technol. Biotechnol. 2008, 83, 769-776.

40. Al Momani, F.A. Potential use of solar energy for waste activated sludge treatment. Int. J. Sustain. Eng. 2013, 6, 82-91. [CrossRef]

41. Krzemieniewski, M.; Dębowski, M.; Janczukowicz, W.; Pesta, J. Effect of sludge conditioning by chemical methods with magnetic field application. Pol. J. Environ. Stud. 2003, 12, 595-605.

42. Legrini, O.; Oliveros, E.; Braun, A.M. Photochemical processes for water treatment. Chem. Rev. 1993, 93, 671-698. [CrossRef]

43. Brigda, R.J. Consider Fenton's chemistry for wastewater treatment. Chem. Eng. Process. 1995, 91, 62-66.

44. Ikehata, K.; Jodeiri Naghashkar, N.; Gamal El-Din, M. Degradation of aqueous pharmaceuticals by ozonation and advanced oxidation processes: A review. Ozone Sci. Eng. 2006, 28, 353-414. [CrossRef]

45. Rice, R.G.; Netzer, A. Handbook of Ozone Technology and Applications; Ann Arbor Science Publishers: Butterworths, UK, 1982; Volume 1.

46. Rodrigues, C.S.D.; Neto, A.R.; Duda, R.M.; de Oliveira, R.A.; Boaventura, R.A.R.; Madeira, L.M. Combination of chemical coagulation, photo-Fenton oxidation and biodegradation for the treatment of vinasse from sugar cane ethanol distillery. J. Clean. Prod. 2017, 142, 3634-3644. [CrossRef]

47. Inchaurrondo, N.S.; Massa, P.; Fenoglio, R.; Font, J.; Haure, P. Efficient catalytic wet peroxide oxidation of phenol at moderate temperature using a high-load supported copper catalyst. Chem. Eng. J. 2012, 198, 426-434. [CrossRef]

48. Maciel, R.; Sant'Anna, G.L.; Dezotti, M. Phenol removal from high salinity effluents using Fenton's reagent and photo-Fenton reactions. Chemosphere 2004, 57, 711-719. [CrossRef] [PubMed]

49. Fenton, H.J.H. Oxidation of tartaric acid in presence of iron. J. Chem. Soc. Trans. 1894, 65, 899-910. [CrossRef]

50. Walling, C. Fenton's reagent revisited. Acc. Chem. Res. 1975, 8, 125-131. [CrossRef]

51. Gosu, V.; Dhakar, A.; Sikarwar, P.; Kumar, U.K.A.; Subbaramaiah, V.; Zhang, T.C. Wet peroxidation of resorcinol catalyzed by copper impregnated granular activated carbon. J. Environ. Manag. 2018, 223, 825-833. [CrossRef]

52. Catrinescu, C.; Teodosiu, C.; Macoveanu, M.; Miehe-Brendlé, J.; Le Dred, R. Catalytic wet peroxide oxidation of phenol over fe-exchanged pillared beidellite. Water Res. 2003, 37, 1154-1160. [CrossRef]

53. Neyens, E.; Baeyens, J. A review of classic fenton's peroxidation as an advanced oxidation technique. J. Hazard. Mater. 2003, 98, 33-50. [CrossRef]

54. Ribeiro, R.S.; Silva, A.M.T.; Figueiredo, J.L.; Faria, J.L.; Gomes, H.T. Catalytic wet peroxide oxidation: A route towards the application of hybrid magnetic carbon nanocomposites for the degradation of organic pollutants. A review. Appl. Catal. B Environ. 2016, 187, 428-460. [CrossRef]

55. Perathoner, S.; Centi, G. Wet hydrogen peroxide catalytic oxidation (WHPCO) of organic waste in agro-food and industrial streams. Top. Catal. 2005, 33, 207-224. [CrossRef]

56. Melero, J.A.; Martínez, F.; Botas, J.A.; Molina, R.; Pariente, M.I. Heterogeneous catalytic wet peroxide oxidation systems for the treatment of an industrial pharmaceutical wastewater. Water Res. 2009, 43, 4010-4018. [CrossRef] [PubMed]

57. European Economic Community. List of Council Directives 76/4647; European Economic Community: Brussels, Belgium, 1982.

58. Feng, J.; Hu, X.; Yue, P.L. Effect of initial solution ph on the degradation of orange II using clay-based Fe nanocomposites as heterogeneous photo-Fenton catalyst. Water Res. 2006, 40, 641-646. [CrossRef] [PubMed]

59. Hartmann, M.; Kullmann, S.; Keller, H. Wastewater treatment with heterogeneous Fenton-type catalysts based on porous materials. J. Mater. Chem. 2010, 20, 9002-9017. [CrossRef]

60. Dantas, T.L.P.; Mendonça, V.P.; José, H.J.; Rodrigues, A.E.; Moreira, R.F.P.M. Treatment of textile wastewater by heterogeneous Fenton process using a new composite $\mathrm{Fe}_{2} \mathrm{O}_{3}$ /carbon. Chem. Eng. J. 2006, 118, 77-82. [CrossRef]

61. Liou, R.-M.; Chen, S.-H.; Hung, M.-Y.; Hsu, C.-S.; Lai, J.-Y. Fe (III) supported on resin as effective catalyst for the heterogeneous oxidation of phenol in aqueous solution. Chemosphere 2005, 59, 117-125. [CrossRef]

62. Wang, Y.; Zhao, H.; Zhao, G. Iron-copper bimetallic nanoparticles embedded within ordered mesoporous carbon as effective and stable heterogeneous Fenton catalyst for the degradation of organic contaminants. Appl. Catal. B Environ. 2015, 164, 396-406. [CrossRef] 
63. Subbaramaiah, V.; Srivastava, V.C.; Mall, I.D. Catalytic wet peroxidation of pyridine bearing wastewater by cerium supported SBA-15. J. Hazard. Mater. 2013, 248-249, 355-363. [CrossRef]

64. Aravindhan, R.; Fathima, N.N.; Rao, J.R.; Nair, B.U. Wet oxidation of acid brown dye by hydrogen peroxide using heterogeneous catalyst Mn-Salen-Y zeolite: A potential catalyst. J. Hazard. Mater. 2006, 138, 152-159. [CrossRef]

65. Hosseini, S.A.; Davodian, M.; Abbasian, A.R. Remediation of phenol and phenolic derivatives by catalytic wet peroxide oxidation over Co-Ni layered double nano hydroxides. J. Taiwan Inst. Chem. Eng. 2017, 75, 97-104. [CrossRef]

66. Rodrigues, C.S.D.; Carabineiro, S.A.C.; Maldonado-Hódar, F.J.; Madeira, L.M. Wet peroxide oxidation of dye-containing wastewaters using nanosized $\mathrm{Au}$ supported on $\mathrm{Al}_{2} \mathrm{O}_{3}$. Catal. Today 2017, 280, 165-175. [CrossRef]

67. Rodrigues, C.S.D.; Carabineiro, S.A.C.; Maldonado-Hódar, F.J.; Madeira, L.M. Orange II degradation by wet peroxide oxidation using Au nanosized catalysts: Effect of the support. Ind. Eng. Chem. Res. 2017, 56, 1988-1998. [CrossRef]

68. Quintanilla, A.; García-Rodríguez, S.; Domínguez, C.M.; Blasco, S.; Casas, J.A.; Rodriguez, J.J. Supported gold nanoparticle catalysts for wet peroxide oxidation. Appl. Catal. B Environ. 2012, 111-112, 81-89. [CrossRef]

69. Hassan, H.; Hameed, B.H. Fe-clay as effective heterogeneous Fenton catalyst for the decolorization of reactive blue 4. Chem. Eng. J. 2011, 171, 912-918. [CrossRef]

70. Han, Y.-F.; Phonthammachai, N.; Ramesh, K.; Zhong, Z.; White, T. Removing organic compounds from aqueous medium via wet peroxidation by gold catalysts. Environ. Sci. Technol. 2008, 42, 908-912. [CrossRef]

71. Ferentz, M.; Landau, M.V.; Vidruk, R.; Herskowitz, M. Fixed-bed catalytic wet peroxide oxidation of phenol with titania and Au/titania catalysts in dark. Catal. Today 2015, 241, 63-72. [CrossRef]

72. Domínguez, C.M.; Quintanilla, A.; Casas, J.A.; Rodriguez, J.J. Kinetics of wet peroxide oxidation of phenol with a gold/activated carbon catalyst. Chem. Eng. J. 2014, 253, 486-492. [CrossRef]

73. Martín, R.; Navalon, S.; Alvaro, M.; Garcia, H. Optimized water treatment by combining catalytic Fenton reaction using diamond supported gold and biological degradation. Appl. Catal. B Environ. 2011, 103, 246-252. [CrossRef]

74. Navalon, S.; Martín, R.; Alvaro, M.; Garcia, H. Gold on diamond nanoparticles as a highly efficient Fenton catalyst. Angew. Chem. 2010, 122, 8581-8585. [CrossRef]

75. Sempere, D.; Navalon, S.; Dančíková, M.; Alvaro, M.; Garcia, H. Influence of pretreatments on commercial diamond nanoparticles on the photocatalytic activity of supported gold nanoparticles under natural sunlight irradiation. Appl. Catal. B Environ. 2013, 142-143, 259-267. [CrossRef]

76. Brust, M.; Walker, M.; Bethell, D.; Schiffrin, D.J.; Whyman, R. Synthesis of thiol-derivatised gold nanoparticles in a two-phase liquid-liquid system. J. Chem. Soc. Chem. Commun. 1994, 7, 801-802. [CrossRef]

77. Primo, A.; García, H. Chapter 18-Supported gold nanoparticles as heterogeneous catalysts. In New and Future Developments in Catalysis; Suib, S.L., Ed.; Elsevier: Amsterdam, The Netherlands, 2013; pp. 425-449.

78. Jiang, G.; Wang, L.; Chen, T.; Yu, H.; Chen, C. Preparation of gold nanoparticles in the presence of poly(benzyl ether) alcohol dendrons. Mater. Chem. Phys. 2006, 98, 76-82. [CrossRef]

79. Turkevich, J.; Stevenson, P.C.; Hillier, J. A study of the nucleation and growth processes in the synthesis of colloidal gold. Discuss. Faraday Soc. 1951, 11, 55-75. [CrossRef]

80. Carabineiro, S.A.C.; Thompson, D.T. Catalytic applications for gold nanotechnology. In Nanocatalysis; Heiz, U., Landman, U., Eds.; Springer: Berlin/Heidelberg, Germany, 2007; pp. 377-489.

81. Haruta, M. Size- and support-dependency in the catalysis of gold. Catal. Today 1997, 36, 153-166. [CrossRef]

82. Haruta, M. Gold as a novel catalyst in the 21st century: Preparation, working mechanism and applications. Gold Bull. 2004, 37, 27-36. [CrossRef]

83. Bond, G.C.; Thompson, D.T. Catalysis by gold. Catal. Rev. 1999, 41, 319-388. [CrossRef]

84. Hodge, N.A.; Kiely, C.J.; Whyman, R.; Siddiqui, M.R.H.; Hutchings, G.J.; Pankhurst, Q.A.; Wagner, F.E.; Rajaram, R.R.; Golunski, S.E. Microstructural comparison of calcined and uncalcined gold/iron-oxide catalysts for low-temperature CO oxidation. Catal. Today 2002, 72, 133-144. [CrossRef]

85. Haruta, M.; Yamada, N.; Kobayashi, T.; Iijima, S. Gold catalysts prepared by coprecipitation for low-temperature oxidation of hydrogen and of carbon monoxide. J. Catal. 1989, 115, 301-309. [CrossRef]

86. Abad, A.; Almela, C.; Corma, A.; García, H. Efficient chemoselective alcohol oxidation using oxygen as oxidant. Superior performance of gold over palladium catalysts. Tetrahedron 2006, 62, 6666-6672. [CrossRef] 
87. Baatz, C.; Decker, N.; Prüße, U. New innovative gold catalysts prepared by an improved incipient wetness method. J. Catal. 2008, 258, 165-169. [CrossRef]

88. Lorençon, E.; Ferreira, D.C.; Resende, R.R.; Krambrock, K. Amphiphilic gold nanoparticles supported on carbon nanotubes: Catalysts for the oxidation of lipophilic compounds by wet peroxide in biphasic systems. Appl. Catal. A Gen. 2015, 505, 566-574. [CrossRef]

89. Lin, J.-N.; Wan, B.-Z. Effects of preparation conditions on gold/Y-type zeolite for CO oxidation. Appl. Catal. B Environ. 2003, 41, 83-95. [CrossRef]

90. Haruta, M.; Tsubota, S.; Kobayashi, T.; Kageyama, H.; Genet, M.J.; Delmon, B. Low-temperature oxidation of $\mathrm{CO}$ over gold supported on $\mathrm{TiO}_{2}, \alpha-\mathrm{Fe}_{2} \mathrm{O}_{3}$, and $\mathrm{Co}_{3} \mathrm{O}_{4}$. J. Catal. 1993, 144, 175-192. [CrossRef]

91. Herzing, A.A.; Kiely, C.J.; Carley, A.F.; Landon, P.; Hutchings, G.J. Identification of active gold nanoclusters on iron oxide supports for CO oxidation. Science 2008, 321, 1331-1335. [CrossRef]

92. Corma, A.; Serna, P. Chemoselective hydrogenation of nitro compounds with supported gold catalysts. Science 2006, 313, 332-334. [CrossRef] [PubMed]

93. Fu, Q.; Saltsburg, H.; Flytzani-Stephanopoulos, M. Active nonmetallic au and pt species on ceria-based water-gas shift catalysts. Science 2003, 301, 935-938. [CrossRef] [PubMed]

94. Rodriguez, J.A.; Ma, S.; Liu, P.; Hrbek, J.; Evans, J.; Pérez, M. Activity of $\mathrm{CeO}_{\mathrm{x}}$ and $\mathrm{TiO}_{\mathrm{x}}$ nanoparticles grown on $\mathrm{Au}(111)$ in the water-gas shift reaction. Science 2007, 318, 1757-1760. [CrossRef]

95. Pérez, P.; Soria, M.A.; Carabineiro, S.A.C.; Maldonado-Hódar, F.J.; Mendes, A.; Madeira, L.M. Application of $\mathrm{Au} / \mathrm{TiO}_{2}$ catalysts in the low-temperature water-gas shift reaction. Int. J. Hydrog. Energy 2016, 41, 4670-4681. [CrossRef]

96. Scirè, S.; Minicò, S.; Crisafulli, C.; Satriano, C.; Pistone, A. Catalytic combustion of volatile organic compounds on gold/cerium oxide catalysts. Appl. Catal. B Environ. 2003, 40, 43-49. [CrossRef]

97. Centeno, M.A.; Paulis, M.; Montes, M.; Odriozola, J.A. Catalytic combustion of volatile organic compounds on $\mathrm{Au} / \mathrm{CeO}_{2} / \mathrm{Al}_{2} \mathrm{O}_{3}$ and $\mathrm{Au} / \mathrm{Al}_{2} \mathrm{O}_{3}$ catalysts. Appl. Catal. A Gen. 2002, 234, 65-78. [CrossRef]

98. Scirè, S.; Liotta, L.F. Supported gold catalysts for the total oxidation of volatile organic compounds. Appl. Catal. B Environ. 2012, 125, 222-246. [CrossRef]

99. Chang, Y.-C.; Chen, D.-H. Catalytic reduction of 4-nitrophenol by magnetically recoverable Au nanocatalyst. J. Hazard. Mater. 2009, 165, 664-669. [CrossRef]

100. Aprile, C.; Corma, A.; Domine, M.E.; Garcia, H.; Mitchell, C. A cascade aerobic epoxidation of alkenes over $\mathrm{Au} / \mathrm{CeO}_{2}$ and ti-mesoporous material by "in situ" formed peroxides. J. Catal. 2009, 264, 44-53. [CrossRef]

101. Cojocaru, B.; Neaţu, Ş.; Sacaliuc-Pârvulescu, E.; Lévy, F.; Pârvulescu, V.I.; Garcia, H. Influence of gold particle size on the photocatalytic activity for acetone oxidation of $\mathrm{Au} / \mathrm{TiO}_{2}$ catalysts prepared by dc-magnetron sputtering. Appl. Catal. B Environ. 2011, 107, 140-149. [CrossRef]

102. Marino, T.; Molinari, R.; García, H. Selectivity of gold nanoparticles on the photocatalytic activity of $\mathrm{TiO}_{2}$ for the hydroxylation of benzene by water. Catal. Today 2013, 206, 40-45. [CrossRef]

103. Martínez, F.; Calleja, G.; Melero, J.A.; Molina, R. Heterogeneous photo-Fenton degradation of phenolic aqueous solutions over iron-containing SBA-15 catalyst. Appl. Catal. B Environ. 2005, 60, 181-190. [CrossRef]

104. Kuznetsova, E.V.; Savinov, E.N.; Vostrikova, L.A.; Parmon, V.N. Heterogeneous catalysis in the Fenton-type system FeZSM-5/ $\mathrm{H}_{2} \mathrm{O}_{2}$. Appl. Catal. B Environ. 2004, 51, 165-170. [CrossRef]

105. Carabineiro, S.A.C.; Machado, B.F.; Bacsa, R.R.; Serp, P.; Dražić, G.; Faria, J.L.; Figueiredo, J.L. Catalytic performance of $\mathrm{Au} / \mathrm{ZnO}$ nanocatalysts for $\mathrm{CO}$ oxidation. J. Catal. 2010, 273, 191-198. [CrossRef]

106. Ge, L.; Chen, T.; Liu, Z.; Chen, F. The effect of gold loading on the catalytic oxidation performance of $\mathrm{CeO}_{2} / \mathrm{H}_{2} \mathrm{O}_{2}$ system. Catal. Today 2014, 224, 209-215. [CrossRef]

107. Drašinac, N.; Erjavec, B.; Dražić, G.; Pintar, A. Peroxo and gold modified titanium nanotubes for effective removal of methyl orange with CWPO under ambient conditions. Catal. Today 2017, 280, 155-164. [CrossRef]

108. Yang, X.; Tian, P.-F.; Zhang, C.; Deng, Y.-Q.; Xu, J.; Gong, J.; Han, Y.-F. Au/carbon as Fenton-like catalysts for the oxidative degradation of bisphenol A. Appl. Catal. B Environ. 2013, 134-135, 145-152. [CrossRef]

109. Alvaro, M.; Cojocaru, B.; Ismail, A.A.; Petrea, N.; Ferrer, B.; Harraz, F.A.; Parvulescu, V.I.; Garcia, H. Visible-light photocatalytic activity of gold nanoparticles supported on template-synthesized mesoporous titania for the decontamination of the chemical warfare agent soman. Appl. Catal. B Environ. 2010, 99, 191-197. [CrossRef] 
110. Rodrigues, C.S.D.; Silva, R.M.; Carabineiro, S.A.C.; Maldonado-Hódar, F.J.; Madeira, L.M. Dye-containing wastewater treatment by photo-assisted wet peroxidation using Au nanosized catalysts. J. Chem. Technol. Biotechnol. 2018, 93, 3223-3323. [CrossRef]

111. Navalon, S.; Martin, R.; Alvaro, M.; Garcia, H. Sunlight-assisted Fenton reaction catalyzed by goldsupported on diamond nanoparticles as pretreatment forbiological degradation of aqueous phenol solutions. ChemSusChem 2011, 4, 650-657. [CrossRef] [PubMed]

112. Galindo, C.; Jacques, P.; Kalt, A. Photochemical and photocatalytic degradation of an indigoid dye: A case study of acid blue 74 (AB74). J. Photochem. Photobiol. A Chem. 2001, 141, 47-56. [CrossRef]

113. Spinks, J.W.T.; Woods, R.J. An Introduction to Radiation Chemistry, 3rd ed.; John Wiley \& Sons Inc.: New York, NY, USA, 1990.

114. Fida, H.; Zhang, G.; Guo, S.; Naeem, A. Heterogeneous Fenton degradation of organic dyes in batch and fixed bed using la-fe montmorillonite as catalyst. J. Colloid Interface Sci. 2017, 490, 859-868. [CrossRef]

115. Navalon, S.; de Miguel, M.; Martin, R.; Alvaro, M.; Garcia, H. Enhancement of the catalytic activity of supported gold nanoparticles for the fenton reaction by light. J. Am. Chem. Soc. 2011, 133, 2218-2226. [CrossRef] [PubMed]

116. Zazo, J.A.; Pliego, G.; Blasco, S.; Casas, J.A.; Rodriguez, J.J. Intensification of the Fenton process by increasing the temperature. Ind. Eng. Chem. Res. 2011, 50, 866-870. [CrossRef]

117. Huang, C.P.; Dong, C.; Tang, Z. Advanced chemical oxidation: Its present role and potential future in hazardous waste treatment. Waste Manag. 1993, 13, 361-377. [CrossRef]

(C) 2019 by the authors. Licensee MDPI, Basel, Switzerland. This article is an open access article distributed under the terms and conditions of the Creative Commons Attribution (CC BY) license (http://creativecommons.org/licenses/by/4.0/). 